\title{
LA FÍSICA DE ARISTÓTELES Y LAS FÍSICAS "ARISTOTÉLICAS" DE OCKHAM
}

Francisco José Fortuny*

StNTESB - Resumen: A partir de una consideracion de la epistemologia cast semiótica de Aristóteles (valora que todo conocimiento y pensamiento inevitablemente están mediados por un conjunto de signos), se observa cue la Physis se inscribe en un itinerario que va del arje noético hasta el télics del Primer Motor. Un concepto fundamental y problematicico es el de continuo, una de cuyas especies, el movimiento, ocupo mucho a los medievales Su tratamiento del continuo con una metafora de la geometría generativa produce un juego dinámico que será luego interpretado de diversas maneras.

PALABRAS-CLAVB - Flosofia Modioval. Fisica. Aristóteles. Guglielmo de Ockham.
ABSTRACT - En esta línea el reduccionismo de Ockham debe interpretarse como una concepción pre-newtoniana de la fisica. Bn su tecria la finaibdad intencional de la mente es prevalentemente y por eso el movimiento es un proceso visto solo desde la mente.. $Y$ el tiempo, que es un momento real de la realidad, previo a toda constderacion humana en Aristoteles, es en Ockham concebidio en y por la dualidad "dato empinioo/estructura formal". Bl lugar "inmóvil" de Aristóteles es en el Venerabelis Inocptor "inmóvil por equivalencis", y como "ac si". Starting from a consideration of the episte. mology almost semiotic of Aristotle the values that all knowledge and thought inevitably are mediated by a group of signs), it is observed that the Physis registers in an itinerary that goes from the noetic arjé to the télos of the First Motor. A fundamental and problematic concept is that of the continuous, one of whose species, the movement, occupled to the medievals a lot. His treatment of the continuous with a metaphor of the generative geometry produces a dynamic game that will be interpretod in diverse ways. In this line Ockharn's reductionism should be interpreted like a pre-Newtonsan conception of the Physics, in his theory the intentional finaity of the mind is prevalently and for that reason the movement is a process only seen from the mind. And the time that is a real moment of the reality, previous to all buman consideration in Aristotle, it is in Ockham concelved in and for the duality "empirical fact/formal structure". Aristotle's "immobile" place is in the Venerabilis Inceptot immobile for equivalence", and like "ac st." KEY WORDS - Mediceval Philosophy. Physics. Aristotle. Willam of Ockham.

* Universidad de Barcelona.

\begin{tabular}{|l|l|l|l|l|l|}
\hline VERITAS & Porto Alegre & v. 44 & n. 3 & Setembro 1999 & p. 727-766 \\
\hline
\end{tabular}




\section{Retorno a los textos originales con sentido histórico total: estricta historiografía}

Tal vez este trabajo pueda parecer insólito. De alguna manera lo es. Se pretende una aportación estrictamente historiográfica en el ámbito de la Historia de la Filosofia. Debe mucho al actual concepto de Historia, a la actual epistemología de la historiografia.

Por contraste, el trabajo se presenta con mucho desapego a la tradición hermenéutica, con muy poca atención hacia los aspectos estrictamente filológicos, con aparente insensibilidad respecto a los grandes portavoces "clásicos" de la intelección de Aristóteles, ${ }^{1}$ desde el omnipresente Tomás de Aquino hasta los E. Zeller, W. D. Ross, W. Jaeger, e incluso, I. Düring o la sintesis reciente de W. C. K. Guthrie, ${ }^{2}$ con no disimulada oposición a todo larvado mecanicismo o cientifismo ideológico.

Si alguna cosa se pretende en estas páginas es una vuelta a los textos originales, sin más mediación - que no es poco - que la clara conciencia de que sólo desde hoy y para hoy puede emprenderse una lectura de venerables textos de más de veinte siglos atrás. Sólo podemos leer aquello que nosotros mismos preguntamos al texto. Pero en ello radica nuestra fidelidad el texto antiguo y a nuestro hoy': en no proyectar sobre el texto visiones del mundo del próximo ayer, que ya nos son tan ajenas como el Aristóteles histórico en si mismo. De este ayer próximo pasado, que no del pasado clásico, resultan magnificos testigos los grandes intérpretes históricos del Filósofo en mucho mayor grado que de la correcta interpretación ipsissimi Aristotelis.

1 Como visłón global de la historiografia sobre Aristóteles, todavia citariamos a $E$. Berti: Aristotele. en "Questioni di Storiografia Filosofica" (V. Mathieu, Editor) Brescia, Bd. La Scuola, vol. I, 1975, p. 247. 270.

2 E. Zeller: Die Philosophie der Griechen in Ihren geschichtlichen Bntwicklung. Leipzig, G. R. Reisland, 1921 (trad. Italiana de Cl. Cesa: La Flosafia del Grecl nel suo sviluppo storico. Parte II, vol. VI: Aristotele e i peripateticf pfu antichi. Firenze, "La Nuova Italia" Bd., 1966). W. D. Ross: Aristotlo. London, Methuen, 1923 (New Yotk, Barnes et Nobel, 1964; trad. ital. de A. Spinelli: Aristotele. Bari, Laterza, 1946). Werner Jaeger: Aristoteles. Grundlegung einer Geschichte seiner Entwicklung. BerIin, Weidmann, 1923 (trad. Itallana de G. Calogero: Aristotele. Prime linee di una staria della sua evolutione spintuale. Firenze, "La Nuowa Italia" Ed., 1935, rlest. 1968. Ingemar Düring: Aristoteles. Darstellung und Interpretations seines Denkens. Heidelberg. Carl Winter-Universitàtsverlag, 1966. (Trad. castellana de B. Navarro: Aristóteles. Exposición e interpretación de su pensamiento. México, U.N.A.M., 1990). Sin embargo en el caso de Düring hernos de hacer constar nuestra evidente deuda de gratitud: el sugirio como minimo la dirección de lectura, si no unas tesis que, quizas, el no haria suyas en la impostación que adquirirán aqu. W. C. K. Guthrie: A History of Greak Phylosophy. Vol. VI, Aristotle. An encounter. Cambridge, University Press, 1981.

3. Forteza: Hermeneutica y epistemología semidica. Barcelona, K.A.L. Ed., 1999. Rste debe ser el momento de hacer constar cuanto debemos en la preparación remota y la redacción de estas líneas al propio Dr. B. Forteza, y a los Drs. M. Candel, A. Grau, L. Roviró y R. Aguila, colegas en el Equipo de Investigación "K.A.L" de la Universidad de Barcelona y coprofesores en un curso de pragmática fllosótica titulado "Fllosofia y Empresa" (1998-99). 


\section{La epistemología casi semiótica del Estagirita: un modelo}

Verosimilmente la Fisica es la gran obra especulativa de Aristóteles, algo así como el estudio de la realidad, flanqueado instrumentalmente por los principios ontológicos previos de una Filosofia Primera y por los principios del discurso en el Organon. Los tres bloques no son en conjunto un sistema filosófico, pero tienen una unidad y un orden natural.

Que las tres grandes piezas de la especulación aristotélica no sea una obra y, menos aún, una obra sistemática, no ha de ser obstáculo para que el historiador y el historiador de la filosofia, desde su presente y metalinguíisticamente, extraiga un muy sistemático modelo del pensamiento del autor. Aristóteles jamás lo habria reconocido; el historiador conoce el lenguaje del Estagirita como nunca él pudo conocerlo reflexivamente.

\section{La epistemología casi semiótica del Estaginita: qué es}

El punto de partida de las reflexiones de Aristóteles cumple lo anunciado por el subtitulo inmediato: el filósofo adopta una epistemología semiótica. El "casi" no matiza el contenido objetivo de la epistemologia semiótica, sino la conciencia subjetiva que podia tener de ella el autor.

Dos aspectos han de ser subrayados. En primer lugar, en qué consiste una tal epistemologia semiótica y qué tipo de conocimiento reflejo de ella podía tener el Estagirita. El segundo aspecto, es constatar la corta función que el Filósofo asigna a tal epistemología y explicar cuándo y porqué la abandona.

La epistemología semiótica radica en valorar que todo conocimiento, todo pensamiento, toda acción racional, está inevitablemente mediada por unos conjuntos de signos. Estos conjuntos semióticos no son ni subjetivos ni objetivos, ya que son anteriores lógica y ónticamente a ambas categorizaciones, ni tienen significación por si mismos, ni su significación es natural o se mantiene intacta más allá de un periodo histórico. Por otra parte, los mismos conjuntos de signos definen los periodos como categoria historiográfica auténtica al ser comparados con conjuntos de signos anteriores o posteriores y mostrarse como incapaces de superposición.

Operacional y derivadamente, la epistemologia semiótica impone no hacer recurso nunca a una "realidad" que no puede aparecer si no es a través de la mediación semiótica. Una mediación, la semiótica, que se presenta como una opción primera y radical de aceptación del valor significativo de un par de signos o de una proposición un poco más compleja, desde la cual, como desde un punto fijo sólido, adquieren significado cierto y determinado, por su topologia, todos los restantes signos del conjunto.

Nótese que este rasgo topológico que vertebra un conjunto semiótico no es otra cosa que la generalización radical de la problemática del espacio. El significado de un signo proviene del "lugar" que el uso le atribuye en el conjunto de los signos del discurso. Por tanto, la mediación de los signos incluye una opción gratuita nuclear de fijación de un centro semiótico inmóvil y una estructura en torno a él de relaciones formales, constitutivas de la toponimia de los signos en el conjunto estructurado. 
Naturalmente, esta es la caracterización de la epistemologia semiótica desde el final del siglo XX. La función que ejerce tal epistemología en nuestro fin de siglo es la de proporcionar una base común para la enorme cantidad de discursos en uso actualmente dentro del ámplio abanico que va desde las ciencias más estrictas hasta la mítica y l'immaginaire del hombre de la calle que todos llevamos dentro.

A la vez, la enorme cantidad de discursos que llegan a nosotros desde la profundidad de la historia, sobre la base de la semiótica tomada como epistemologia, va encontrando remanso para cada uno en nuestro acervo cultural. La base única de los discursos permite calibrar extrínsecamente los desplazamientos de los signos relevantes y valorar intelectualmente la repercusión semántica y pragmática en los signos individualizados como conceptos y en la globalidad de los discursos."

Calibrar extrínsecamente no significa que se trate de una operación meramente calculistica, sino que la acción de entender se realiza desde una completa epojé de cualquier conjunto categorial del sujeto pensante psicológico, acorde con la fórmula más radical de la fenomenologia de Husserl, una fenomenologia que semióticamente alcanza hasta la autoconstitución toponímica de los signos en los discursos concretos, previa a la catalogación de las categorias y las ideas o conceptos.

\section{La epistemología casi semiótica del Estagirita: en qué momento}

Afirmar que Aristóteles piensa exactamente lo que se presenta en el apartado anterior o que piensa algo ténuemente idéntico a lo largo de todo su proceso de comprensión de la realidad, seria asentar un anacronismo. Aristóteles cree conocer la realidad y, ciertamente, la realidad en si misma. Y sabe y cree conocerla desde el mismisimo comienzo de su discurso: el fin está en los inicios tanto como al final de un proceso noético.

Aristóteles también conoce la mediación lingüistica del conocimiento y una mediación que él considera de fuerte intensidad. De la suficiente intensidad como para que crea que un discurso al que todos recurrimos, que "todos decimos", ha de ser tomado inevitablemente como una manifestación fehaciente de la realidad

4 "Calibrar extrinsecamente" no significa que se trate de una operación meramente accidenta. Se quiere acentuar que está en uso la fórmula más radical de la fenomenologia de Hussenl. Ouizís se referia a algo de esto el propio Aristóteles cuando reconoce que habrá de aportar una "reflexión esotérica" a los temas de la Fisica (Phys. IV, 10, 217b 30-31).

5 En efecto, combenza ser valorada linguifsticamente una "semántica textual" y una "pragmática textual". Si se toma literalmente que la significación de un signo linguilistico es su uso (L. Wirtgons. tein), la totalidad del texto impone a los signos una significacion propia del texto e imposible en cualquier otro texto. Bn el texto como conjunto se pueden dar niveles de lenguajes y metalenguajes que nunca serán perceptibles signo a signo o frase a frase. Nótese cuan atrás va quedando toda la filosofla analitica del lenguaje ordinario, incluso de cara a la misma filosotla del lenguaje. Vease, por ejemplo, S. J. Schmidt (München, 1973): Teoria del texto. Madrid, Cátedra, 1973. T. A. Van Dijk (London, 197-): Texto y cantexto. Madrid, 1980. Greimas, A.J. (1976): "La semítica del texto". 1983. Lyons, John. (1981, Cambridge): "Lenguaje, significado y contexto". Madrid, 1983. G. Rigau $i$ Olver: Gramática del discurso. Barcelona, 1981. Q. Reyes: La pragmática lingulistica. Bl estudio del uso del lenguaje. Barcelona, 1990. 
en sí. Destaquemos la fuerza de la argumentación: és necesario un discurso porque inevitablemente y de hecho todos nos encontramos haciendo uso de él, un determinado y concreto discurso: tres puntos de fuerza en la argumentación, todos, de hecho e inevitablemente.

\section{"No es posible discutir trayendo a presencia los objetos mismos"}

Pero los discursos que "todos usamos" llegan a ser contradictorios entre si: la realidad se opone a la realidad. Hasta tal punto la realidad se opone a la realidad que

"En efecto, como no es posible discutir trayendo a presencia los objetos mismos, sino que empleamos los nombres en lugar de los objetos, como unos símbolos, creemos que lo que ocurre con los nombres ocurre también con los objetos. Pero no hay tal semejanza: en efecto, los nombres y la cantidad de enunciados son limitados, mientras que los objetos son numéricamente infinitos. Es pues necesario que un mismo enunciado y un único nombre signifiquen varias cosas ${ }^{-5}$ (Soph. El. 165a 6-13).

Es inútil apelar a la realidad precisamente porque es ella quien se contradice en sus manifestaciones en el discurso humano inevitable.' En esta situación, Aristóteles adopta dos posiciones. En primer lugar, el hombre sólo es capaz de doxa y nunca de verdadera episteme," pero tal opinión ha de ser bien fundamentada. En segundo lugar, ésta fundamentación no es fruto de la realidad misma, ya que es ella quien se manifiesta contradictoria, ni de un o unos conceptos primeros fundamentadores, ni mucho menos cultural y fáctica, sino que la fundamentación es una elaboración o construcción intelectual humana.

En este momento, como consecuencia de la segunda opción reseñada, Aristóteles inicia su singladura semiótica. Y abandonará su méthodos semiótico tan pronto como quede establecido semióticamente que existe un Motor Inmóvil Primero, el cual es causa final para un arjé noético que se realiza a sí mismo en la Physis.

En el momento en el que, gracias a la fundamentación unificadora de la totalidad de los discursos que todos usamos, la Physis queda inscrita como el itinerario desde el arjé noético hasta él mismo como télos, noéticamente realizado y siempre realizando, Aristóteles abandona su inicial epistemologia semiótica. A partir de este momento acepta la dialéctica dinámica de los discursos comunes como la epifania intelectual de la realidad en sí misma. Aristóteles evita cuidadosamente cualquier dualidad platónica de mundos.

- e)peil galr oujk el/stin au/nal tal pra/gmata diale/gesthai fe/rontaj, a)llal toi-1 olno/masin a)ntil twen pragma/twn $x r w / m e q a$ w(j sumborlotj, tol sumbai-non e)pil tw-n o)noma/twn kail e)pil tw-n pragma/twn h(gou/meqa sumbai/nein, [kaqa/per e)pil tw=n yh/fwn toimj logizome/noijl. tol d' oujk e)/stin o/moian: tal meln galr o)no/mata pepe/rantai kail tol twen lo/gwn plh=qoj, tal del pra/gmata toln a)rithmola a/peira/ e)stin. alnagkaion ouj-n plei/w toln aujtoln lo/gon kaf tou)/noma tol eiln semai/nein.

Ү

Las cosas que inicialmente nos son claras y evidentes son mis bien confusas. (Arist: Phys. 184a 125)

- El saber no necesita ser otra cosa que mera opinión... firmemente fundada. (Arist: Gran Btica II, 6, 1201 b 4-9, o Etica nicomaquea 5, 1146b 27-31). Cfr. Düring, L.: p. 60-61 y 28 
Del Aristóteles semiótico se pasa, en una inversión copernicana a partir del noésis noéseos, zooé lógico y óntico, a un Aristóteles dialécticamente realista. Jamás el Filósofo es "realista" a secas como lo son algunos medievales: él modeliza una Physis con el recurso a un modelo dialéctico fisiológico, nunca se quedará en un discurso a-dialéctico que le encerraria en la estática de una morfología de la Physis aparente. Aristóteles verá repetido en cada instancia de su doctrina el esquema paradigmático de su noésis noéseos, zooé.

\section{La epistemología casi semiótica del Estagirita: en qué consiste}

Pero ¿en qué consiste y se manifiesta la epistemología semiótica de Aristóteles si él no tiene consciencia de ella? En pocas palabras, consiste en que inicialmente no conoce otra realidad que la de los discursos fácticos, sólo dispone de textos sobre la realidad. No en vano el Filósofo es "El Lector" por antonomasia para Platón.' Y Aristóteles, conscientemente, hace lo único que se puede hacer con un conjunto de textos contradictorios, que generan paradojas: buscar su unidad lógica sin negar ninguno en una reducción imposible y superar la contradicción simple mediante la formulación intelectual de una base común, la cual le permita una relación dialéctica entre discursos contradictorios.

En esto consiste la epistemologia semiótica momentánea de Aristóteles: en trabajar conscientemente sobre la única realidad de los discursos, mediante recursos intelectuales discursivos. Sus principios en esta etapa o momento teórico son: "Pues cada uno aporta algo propio a la verdad." dicen de muchas maneras. ${ }^{\text {"H }}$

De acuerdo con el momento epistemológicamente semiótico, 1) Aristóteles "construye", con explícita consciencia de ello, una base discursiva común para todos los discursos que ha debido aceptar de sus antecesores y que glosa doxográficamente en el Libro I de la Fisica. El resultado de la construcción aristotélica es el paradójico concepto de "continuo", con su extraña génesis, su ambíguo estatuto óntológico y sus inesperadas sugerencias e implicaciones.

Un paso más allà del momento primero semiótico, 2) surge el motor inmóvil, y 3) el Primer Motor Inmóvil que comportarán el salto desde la semiótica y la construcción de un modelo mental hasta la realidad en si, intelectualmente modelizada. Ambas nociones de motor son exigidas por la noción constructa de "continuo", de absoluta centralidad en todo el pensamiento del Estagirita. Bañandolo todo, como un principio fundamental para la construcción semiótica, hay un pequeno texto omnipresente: Phys. 222a 19-20.

- $\mathrm{Si}$ es que se ha de aceptar como veridica la anéodota de la Vita martiana Aristócelis. Vide L. Düring: Aristoteles, O, c. p. 28 y 368 .

10 Etica cudemia I, 6, 1216b 26-33. Ctr. Daring, L: Aristótoles. p. 47, 61, 626, 710, 771 etc.

14 Phys. 185b 6-25. Y, "se dicen de muchas maneras", se usan de muchas maneras, muchas cosas, prácticamente todos los conceptos importantes de la Fisica; el "ser" (Phys. 185b 6, 186a 31-34) y el "Llegar a ser" (Phys. 190a 31), como lo "uno" y lo "uno y múltuple" (Phys. 185b 6 y 25 ss.; 227b 2 ). Se dice de muchas maneras, tambien, el infinito y la potencia (Phys. 255a 31, cfr. Met. 1019a 11 ss.), como primero (Phys. 260b 16) y continuo (Phys. 200b 25; 226b 19-227b 3; 228a 228b 18). Inchuso la inefable "materia" se dice de muchas maneras (Phys, p.47 y Düring, p. 62-63), etc. Cfr. Düring, 1.: Aristoteles. pp. 119; sobre las palabras como más escasas que las cosas y los fenómenos, de donde la importancla de las diversas maneras de dectr (Soph. Bl. 165e 7) ctr. Duling. Anistóteles, O. c. p. 117. 


\section{Primera aproximación al concepto aristotélico de continuo}

Es bien conocido de todos el texto fundamental de Aristóteles acerca del continuo, synechés, de Phys. V, 227a 10:

"Lo continuo es una subdivisión de lo contiguo: así, por ejemplo, digo que una cosa es continua con otra cuando sus limites que se tocan entre si llegan a ser uno y lo mismo y, como indica la palabra, se "con-tienen" entre si, pero si los extremos son dos no puede haber continuidad. Según esta definición resulta evidente que la continuidad pertenece a aquellas cosas en las que en virtud de su naturaleza llega a haber una unidad por contacto. Y, asi como lo continuo lega a ser uno, asi también un todo será uno, por ejemplo mediante el enclavado, el encolado, el ensamblaje o la unión orgánica." ${ }^{11}$

El entorno de este texto fundamental lo proporciona una constelación de conceptos relacionados en el uso cotidiano: las cosas están "juntas" (háma), "separadas" (choris), en "contacto" (háptesthai), en sucesión (ephexês), contigua (echomenon). Nótese que se trata de un conjunto de términos inequivocamente espa-

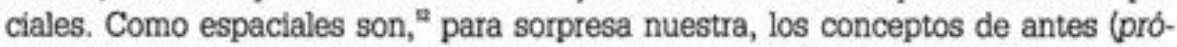
teros) y después (hústeros).

Nunca será suficientemente destacado este carácter espacial de las nociones básicas en torno al continuo, tanto para la comprensión de la génesis del concepto de continuo en Aristóteles, como para entender cómo los bajo medievales pudieron tan fácilmente reducir la Fisica del Estagirita a un paradigma mecánico exclusivo. Muy patentemente, Aristóteles aplica su norma epistemológica: de lo más claro para nosotros a lo más claro de por sí. En la misma cita sobre el antes y después espacial se subraya que lo auténticamente "continuo" es la magnitud y de la magnitud deriva la continuidad del movimiento y del tiempo.

\section{"El antes y después en el movimiento,... pero su ser es distinto"}

Y destaquemos de nuevo: el texto concluye con una frase que se va repitiendo machaconamente pese a que vaya cambiando con colores locales cada vez:

" $\mathrm{El}$ antes y después en el movimiento, cuando el movimiento es lo que es (hó pote on), es movimiento, pero su ser es distinto y no es movimiento." ${ }^{\text {"b }}$

1 Aristóteles: Phys. IV, 11, 219a 15-20: "Ahora bien, el antes y después san ante todo atributos de un lugar, $y$ en virtud de su posición relativa. $Y$ puesto que en la magnitud hay un antes y un después, también en el movimiento tiene que haber un antes y un después, por analogia con la magnitud. Pero tamblén en el tiempo hay un antes y un después, pues el tiempo sigue siempre al movimiento".

5 Aristoteles: Phys. IV, 11, 219a 20-22 y notese que una frase paralela pero con color temporal explicito, y ya no cinético está poco más allá: $219 \mathrm{~b} 12-15$; la tormula cinegética-cronológrica en $229 \mathrm{~b}$. Quizás más ajustadas, las traducciones de los dos textos publicadas por J. L. Calvo Martinez dicen respectivamente: "Y el antes y el después en el movimiento son movimiento con respecto a aquello siendo lo cual' son antes y después; pero su ser es diferente y no es el movimiento." "QI 'ahora' es, en cierto sentido, el mismo y en otro sentido no el mismo: en la medida en que se da sucesivamente, es diferente (y esto seria para él 'ser un ahora') pero en la medida en la que es un ahora con respeto a "aquello siendo lo cual' es lo mismo" 
En general los siete textos de la Physica con la fórmula "hó pote ón / én" son variantes del paradigma aristotélico " $\mathrm{x}$ e y son tal, pero hó pote ón son diferentes". Y, en general, el hó pote én representa la "cosa" móvil, fácil de conocer para nosotros. Se explicita claramente en 220a 1-8:

"Bs evidente también que si no existiera el tiempo no existifía el 'ahora', e igualmente, si no existiera el 'ahora' no existiria el tiempo [...]. Pues el tiempo es el número de la traslación, y el 'ahora' corresponde a lo que se traslada como una unidad del número. Pero además el tiempo es continuo en razón del 'ahora' y se divide en 'ahoras', pues ello tambien corresponde a la traslación y a lo que se traslada. $Y$ es que movimiento y translación son una y la misma cosa en razón de lo que se traslada, porque esto es único (aunque no con respecto a 'aquello siendo lo cual' [hó pote ón] se mueve, pues podria haber discontinuidad, sino por definicion. ${ }^{-14}$

A la luz de este conjunto de textos, que destacan la prioridad del lugar en el antes/después, como señalan la funcionalidad de "realidad móvil" del "ahora" (nun, nunc) y también imponen el estricto paralelismo y gradación ordenada del lugar, el movimiento y el tiempo, que afecta identicamente a sus cisuras respectivas, el punto, el momento y el ahora, es posible extraer unas conclusiones.

\section{La metáfora de la geometría generativa y el continuo aristotélico}

En efecto, 1) Aristóteles trata del continuo definiendolo según una metáfora ya corriente entre los pitagóricos: la que da lugar a la geometría generativa, el movimiento del punto genera la línea, el de ésta el plano, y el deslizamiento del plano ocasiona el cuerpo. Igualmente, el punto, el ahora y el móvil generan los continuos fisicos. 2) Cómo los pitagóricos, el Estagirita considera el número numerado como una cisura sin magnitud, $y$ acorde con ello también considera meras cisuras el punto geométrico del espacio-lugar, el momento del movimiento y el ahora del tiempo. Pero, también como los pitagóricos, 3) considera el número que numera como nombre de una magnitud medida, que incluye las menores que ella y es incluida por las mayores. 4) En este caso el punto geográfico, el momento extenso del movimiento y el largo ahora de una cantidad de tiempo, son dos puntos, momentos o ahoras que son sólo uno e idénticos, pese a que por si mismos, por su definición esencial, son diferentes."

4 Aristóteles: Phys. IV, 11, 220a 1-8: "Faneroln del kail o/fit eil/te xro/nol mhl eij/h, tol nu-n oulk a)/n 220a eij/h, eil/he tolnu-n mhlei//h, xro/noj oulk a/ln eil/h: a(/ma galr w//sper tolfero/menon kainh(fota/, oul/tw) kailo(a)rithmoly o(tou= ferome/nou kailo(th-j foraw). xro/nof meln galt ofth-j fora-j a)rithmo/], tolnu-n delwo tolfero/menon, oi(-on monal alrithmou=. (5) kail sunexh// te dhi

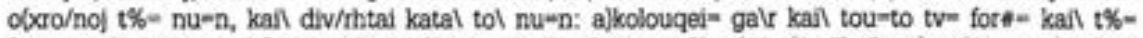
ferome/n\%. kail gals h/ki/nhsil kafl h(foralmi/a t\%- ferome/n\%, o/ti e//n "kail ou) $\mathrm{x}$ o/ pote o)/n kail galt alln diali/poia)lalt $\%=10 / g \%$ :

is Adviertase que esta descripción tan abstracta no es ni denota otra cosa que el juego infantil de trazar circunferencias y letras en la noche con la punta incandescente de un palito encencido. EI punto de luz es el mismo u otro-segùn se lo valore ónticamente o topoldgicamente. Con agudeza $\mathrm{R}$. Brague (Du ternps chez Platon et Aristote. Paris, P.U.F., 1882, p. 129) hacia notar que Aristóteles argumenta aceptando con los solistas que Socrates en Atenas o S6crates en Corinto no eran lo mismo. $\mathrm{Y}$ este es el trasfondo del complicado y central-textito dialéctico que veremos después. 
Y, precisamente, este juego dinámico sobre un paradigma espacial de tiempo y de movimiento, montado a raiz de un hecho mental inevitable ya que todos usamos los dos equivocos discursos de la cisura y la magnitud, con variantes e intermedios múltiples, 5) genera o construye el extraño concepto de continuo. A la vez, el continuo halla su definición en el paradigma "antes-después y uno" gracias a la movilidad y heterogeneidad natural de las tres cisuras correspondientes a lugar, movimiento y tiempo.

Aristóteles, pués, genera el concepto de continuo tal como los geómetras pitagóricos construfan las "realidades" geométricas: línea, plano, cuerpo. ¿ Procederíamos nosotros así? ¿Podriamos ni tan sólo plantearnos este proceder more geométrico? ¿No implicará graves consecuencias, fatales debilidades del discurso aristotélico, esta forma de pensar del Filósofo?

Estas preguntas nos obligan a plantear otros dos pasos aristótelicos: a) cuál es la base formal del proceso de razonamiento de Aristóteles frente a la multiplicidad de discursos; b) como su extraño constructivismo se vuelca en una realidaci nuoménica, y ya no fenoménica, para los discursos que todos usamos; o en virtud de qué, lo recibido como fenómeno, se erige en unidad nouménica, pese a no dejar de ser doxa bien "fundada".

\section{La base del continuo:}

\section{"división y unificación son lo mismo con respecto a lo mismo"}

El texto completo asumido en el subtítulo ínmediatamente superior es digno de toda atención:

La divisjon y la unificación son lo mismo y con respecto a lo mismo, pero su ser es distinto." " e)/sti del tau)tol kail katal tau)tol h(diai/resij kail h(e//nwsij), tol d' ei)=nai ou) tau)to." [Phys. 222a 19-20]

Un texto que se complementa, poco más allà y dentro del mismo tratado sobre el tiempo, con la explicación:

"Una cosa es la misma que otra si no se distinguen por una diferencla especifica, pero no si se distinguen,... no se distinguen por la figura, sino porque están bajo una y misma division. [...] pero no son el mismo diez, pues las cosas de las que se predica son diferentes,..." | Phys. IV, 14, 224a 6-11]"

Entre uno y otro texto viene a quedar claro que sólo se puede dividir aquello que forma parte de una unidad y que, a la inversa, solo se unifica lo que es diferente: en apariencia, una tautologia intrascendente. Pero reconsideremos el texto primero.

" "el/sti del tau)tol kail katal (20) tau)tol h(dial/resij kail h(e//nwsij, tol d" eij)=nai ou) tau)to." 


\section{La función genética lingüistica \\ del uso discursivo y la categorización del nombre usado}

En efecto, división y unificación son lo mismo" considerados como una función genética linguística que da lugar, en el caso del texto, a la multiplicidad o la unificación de las unidades de tiempo. Sin embargo, la unidad de función constructivista en el discurso concreto no altera el "ser" predicamental de la división o la unificación: la definición esencial de cada uno, es diferente y aún opuesta. Y esta oposición, precisamente, hace posible la unidad de funciones de una y otra acción intelectual.

Aristóteles, pues, recogería en esta breve frase, y por enésima vez, su procedimiento de unificar funcionalmente en el metadiscurso para destacar la diferencia en la ontología fenomenológica de los discursos tradicionales." Esta frase sintética explica el tratamiento que antes (222a 10ss.) dió al "ahora" y los "ahoras", comparandolos con el punto, un elemento geométrico, y a la geometria generativa, en el que el proceso constructivista obrado por el lenguaje" sobre los ahoras era más fácilmente perceptible "para nosotros".

\section{La claridad del punto y la línea es más aparente que real}

Sin embargo, bien pensado, la claridad del punto y la línea es más aparente que real. No es más "evidente", ni menos forzando el continuo del espacio que el del tiempo; no es este un continuo más irreal o ideal, más "del alma inteligente", que el continuo geométrico de la linea; no está en un verdadero tercer nivel, como parecen sugerir algunas frases aristotélicas - y de Ockham, en quien es más normal verlo recogido asi - al relacionar el movimiento con el tiempo. Tan artificioso es captar la continuidad del espacio, incluso sensible y no sólo geométrico, que advertir la del tiempo o del movimiento. La creciente consciencia de esta igual dificultad a partir de la pérdida de la inmediatez del mundo sensible, será uno de los más potentes motores del pensamiento filosófico hasta llegar a nuestros días, con un "mundo virtual".

Movimiento, lugar y tiempo son tres modos irreductibles de la realidad de la Physis, como el noesis noéseos, zooé son tres modos del arjé, acto único y simplicísimo. Todo el esfuerzo de Aristóteles radica en pasar de "lo claro en un primer momento", pero "más oscuro después", por el camino ya trillado de la geometría

7. El uno mismo, como el ser, se dicen de muchas maneras. Phys. 185b 6-25. Y "se dicen de muchas maneras", también, en la Phys, el "ser" (Phys. 185b 6, 186a 31-34) y el "legar a ser" (Phys. 190a 31). como lo "uno" y lo "uno y multiple" (Phys. 185b 6 y 25 ss.; 227b 2). Se dice de muchas maneras, también, el infinito y la potencia (Phys. 255a 31, cft. Met. 1019a 11 ss.), como primeto (Phys. 260b 16) y continuo (Phys. 200b 25; 226b $19-227 \mathrm{~b} 3 ; 228 \mathrm{a} 228 \mathrm{~b}$ 18). Incluso la inetable "materia" se dice de muchas maneras (Phys, p. 47 y Düring, p. 62-63), etc. Cfr. Düring, L.: p. 119, sobre las palabras como mís escasas que las cosas y los fenómenos, de donde la importancia de las diversas maneras de decir (Soph. El. 165a 7) cfr. During p. 117.

* Pues cada uno aporta algo propio a la verdad. Etica eudemia I, 6, 1216b 26-33. Cfr. Düring, L: Aristcteles, o. c., p. 47, 61, 626, 710, 771.

"Sobte la "flosotia del lenguaje" en Aristóteles, es magistral la síntesis de Düring, L: Aristótoles, o. c., p. 114-121. 
generativa, al bien acotado concepto de "continuo", como aquella base común y dinámica que permite vincular los tres modos fenomenológicos de la Physis en una unidad real y no meramente hipotêtica, como era la del alma cósmica platónica.

Bl ámbito del espacio y la modelización geométrica se le aparecen a Aristóteles como aquel metalenguaje que le permite, con evidencia intelectual, una génesis unitaria y omnicomprensible de las realidades fisicas que el discurso se esfuerza en declarar de forma aislada, sucesiva, confusa y contradictoria.

\section{El proceso del pensamiento aristotélico}

Comienza Aristóteles a) por unificar las tres grandes manifestaciones o modalidades de los continuos físicos, en una dialéctica de la unidad como sintesis de la unificación y la división. Pasa luego b) a realizar idéntica acción intelectual de unificación dialéctica - nunca "reducción", siempre en el plano de la pluralidad legítima de discursos - de las varias "enciclopedias" dentro de cada contínuo. Y, en tercer lugar, c) nunca Aristóteles pierde de vista que la geometria genética de los continuos se fundamenta en la autogénesis necesaria (la "argumentación exotérica", 217b 30-31, quizás?) del noésis noéseos, zooé, el gran continuo noético de fondo que corre entre el arjé y el telos, la pareja de conceptos tan usada en torno a Phys. 222a 11: e)/sti galr tou= meln a)rxh/, tou= del teleuth $/$.

Desde esta perspectiva el pequeño párrafo que nos ocupa - Phys. 221a 19-20 - resulta ser una pequeña maravilla de potencia intelectual y, a la vez de laconismo: todo el aristotelismo fisico, epistemológico y fundante o primero, y todo el aristotelismo como heredero de Platón y padre del neoplatonismo, está condensado aqui, sin matices, sin duda, pero también sin sombras ni oscuridades:

\section{Unificación dialéctica de las "enciclopedias" dentro de cada gran contínuo discursivo}

El "ahora" es la categoria mental geométrica con la que se genera el continuo del tiempo. Si se aplica al "ahora" la dialéctica paradigmática abstracta de la densa y omnipresente fórmula de Phys. 221a 19-20, advertiremos cómo Aristóteles se sirve de ella para dar cuenta de la multiplicidad de enciclopedias del tiempo y del ahora.

En el mismo párrafo que sigue a la fórmula, se constata que Aristóteles la aplica de dos maneras bien dispares. Ciertamente le otorga una función fundamentadora del ahora / ahoras. En realidad se trata de lo mismo en el caso del "ahora" y en el de los "ahoras". En el caso del "ahora": la unidad por continuidad en un ahora único, tiempos simultáneos (219b 10-15), y en 220b 1- tiempo largo o breve y rápido o lento. En el caso de los "ahoras", la división por duplicación de ahoras-límite en los extremos en contacto de unidades de tiempo (219b 15-30) y el carácter numérico de tiempo en razón de los "ahoras" (220b 4-5). Pero de una segunda manera, el ahora soporta otra expresión temporal: "en un dia" o "alguna vez en relación con un ahora fundamental", con sus propias características de uso (219b 18-32). 
Y asi seguirán las enciclopedias variadas del tiempo, muchas y muy ricas de matices en Aristóteles, gracias al juego dialéctico del unir y dividir en torno a la cisura llamada "ahora". En modo alguno, Aristóteles reduce el tiempo a un monocromo y homogéneo movimiento de "horas" de reloj mecánico, la menos humana y la menos interesante de las enciclopedias temporales hasta hace cuatro dias.

\section{"[...] pero no se distinguen por la figura, sino porque están bajo una y misma división"}

El trasfondo de los textos de las enciclopedias del tiempo siempre es: 1/ el concepto de continuo ( - def. "Una cosa es continua con otra cuando sus límites que se tocan entre sí son uno y lo mismo" (227a 10-11) y $2 /$ el principio semiológi$\infty$ (e.d.: "la división y la unión son lo mismo y respecto a lo mismo, pero su ser es distinto" (222a 20)).

Y se puede seguir muy bien esta constante presencia de un concepto de contínuo y de un principio semiológico - que, en el fondo, se identifican como nombre abstracto y regla operativa concreta, cara y cruz de lo mismo - en los párrafos de $223 \mathrm{~b} 30$ - 224a 16. Estos párrafos culminan en la frase ya aducida al iniciar la reflexión sobre el continuo en este trabajo: Phys. 224a: "... pero no se distinguen por la figura, sino porque están bajo una y misma división".

\section{El problema de las cisuras en los tres continuos físicos}

Las cisuras en los continuos físicos son el punto, el momento del movimiento y el ahora. Pero es el sujeto pensante quien puede determinar qué es cisura interruptora y qué no lo es, si identifica límites o no los identifica, incluso si hay contiguilidad o no entre los extremos. Con más precisión, es el sujeto quien puede determinar si la cisura actua como doble término o como término idéntico, y qué es lo que determina que el término de una parte contiguo al término de la otra, sean o no "lo mismo" o lo "otro". Y esto por mucho que Aristóteles hable de un continuo "natural".

$\mathrm{Y}$ esto es precisamente lo que hace que el sujeto se enfrente con una contigüidad o con una continuidad, con varios todos o con un único todo. Como todo concepto importante, las "diferencias" se dicen también de muchas maneras. Los textos, antes aducidos, dan como diferenciadores: las cosas o referentes del "diez", la relación de ángulos y lados en los triángulos, no en cuanto son figura (que es única, la de triangulo) sino de elementos diferentes del continuo de los triángulos que pueden ser diferentes (también por tamaño, color, soporte,...saldrian diferencias rupturistas de continuos).

Pero en todos los casos es verdad que "están bajo una y misma division" de la unidad de un continuo, potencialmente divisible. La unión y la división es lo mismo y respecto a lo mismo porque es la definición de continuo, un constructo en vistas a recoger la oposición en la unidad, e incluso es la definición de " juego" semiótico, la unidad de los signos y de su división determinante del todo. Y ahora se anhade, a la vista de las muchas enciclopedias que el Filósofo distingue y conserva cuidadosamente, que quien maneja las cisuras del continuo es un sujeto. 


\section{El sujeto último y verdadero del "discurso" polifónico de la Physis}

El problema no es saber quien "habla": para Aristóteles, como para nosotros, el locutor es el individuo singular si el discurso es nuestra locución mental, verbal o escrita. El problema es quien tiene la última palabra. El sujeto último y verdadero del discurso polifónico de la Physis y en qué sentido es sujeto y es el último, no es el mismo en Aristóteles que en nosotros, en el siglo XX. Para el Filósofo, siguiendo a Platón, pero de manera muy diversa, el sujeto último es el Alma o la Vida cósmica. Para nosotros es la subjetividad noética e histórica de cada individuo humano. Entre los griegos y nosotros, múltiples esquemas epocales de conocimiento del mundo y del yo.

Igualmente Aristóteles ¿conocia y aplicaba la epistemologia semiótica como en el s. XX? No, ciertamente, pero, a diferencia de los mecanicistas modernos, presta una aguda atención a la globalidad del lenguaje del hombre y a sus discursos globalizadores del saber. $Y$ sabe perfectamente que un signo no es necesariamente el nombre de un denotado estable (un "esto"

El Filósofo sabe, por simple claridad mental humana, que una gran cantidad de signos verbales nombran precisamente una función discursiva, o explicitan los pasos del proceso de su vigencia, o los momentos de su uso correcto en el discurso concreto, o las reglas y códigos constitutivos de su definición recursiva. Y utiliza todos estos recursos discursivos para unificar la pluralidad fenomenologica en un todo viviente y real. Bl Filósofo actua muy a la inversa de los medievales, de Ockham en concreto, como veremos. Han sido necesarios seiscientos años más después de Ockham para reconocer en Aristóteles la presencia de una semiótica implicita del pensar humano.

\section{Una función eminentemente "formal" del 'Nous-Logos': poner los límites, "medir"}

Por esto, Aristóteles acentua la expresión "medir" y el "número" en el caso del tiempo. Pero 1) ni es el "medir" mecanicista, 2) ni es el "número" de las unidades que interpretan cuantitativamente las variables de un algoritmo algebraico.

Se trata del "medir" propio del Noús-Lógos como tal, y un "medir" que es "crear" en el Alma cósmica. Bl Noús-Lógos, la segunda hipóstasis de los neplatónicos no tiene una función dinámica ní ontizadora. La función de dinamizar es propia del Alma cósmica; la de dar el "ser uno" lo es del Uno, por ejemplo en el Liber de Causis. La de la Inteligencia es, en el mismo autor anónimo, una función eminentemente "formal": poner los limites que determinan la capacidad de presencia de bondad con la que en cada singular real se espejea y manifiesta el Bien total. La Inteligencia "mide" formalmente, y acota mediante la definición esencial, como si fuera el lugar de cada individuo.

* Cfr. Düring, L: Aristóteles, o. c. p. 364 . Este será un punto altamente equivoco de sintonia aparente y total contraste real entre Aristóteles y Ockham; una oposición diametral en razón de unas epistemologjias generalmente latentes pero totalmente divergentes; en este caso una simple denotación de un ente concreto ủnico, el "esto", apunta a "realidades" contradictorias. 
Pero es en la Physis, en la "corteza del Alma", en donde se manifiesta y radica ónticamente la pluralidad; el discurso del Noús-Lógos único en la pluralidad sucesiva ordenada es la misma "corteza del alma", la Physis. Ordenar, "numerar" concretamente la pluralidad sucesiva, es obra del Alma, es la Vida en la Physis. Aristóteles, primaria y casi exclusivamente, atribuye al Alma la "numeración" esencial para el tiempo; sólo una vez, y aún simultáneamente con el Alma, a la inteligencia.

\section{Una interpretación rara a los ojos de un historiador: la modernidad de Aristóteles}

Y esto tamblén es importante para valorar la semántica real de los términos en la Fisica de Aristóteles; para dirimir, en definitiva, quién es el sujeto último y verdadero del discurso sobre la Physis, la Fisica: quien numera el movimiento, quien mueve, quien ubica y localiza. Numerar el movimiento lo hace el alma, según el Filósofo.

Pero Aristóteles no acepta la tríada platónica de Bien, Demiurgo y Alma; más concretamente, no acepta la fundamentación del movimiento en el Alma o Vida cósmica que teoriza Platón. Y, sobre esta base, generalmente se concluye que el alma de la que habla Aristóteles no será la platónica, sino la personal, olvidando que esta fue en su momento la opción novedosa de la Edad Media.

Pero no es inevitable que Aristóteles sea tan próximo a la Modernidad y al conocimiento subjetivo propio de ella. Mejor, es impensable un tal anacronismo y, por lo contrario, parece mucho más razonable que sea una interpretación neoplatonizante la que ofrezca mayores garantias históricas de verosimilitud al acercarse al Filósofo. Durante quince siglos, hasta el siglo XII, nadie separó al genial discipulo de su maestro; se le tenía como el máximo expositor de Platón, muy fiel a él pese a sus aportaciones geniales. Y, efectivamente, cerrado el paréntesis que va desde el siglo XII hasta la obra de W. Jaeger, se recupera un Aristóteles platónico durante toda su vida y reformulador, substancialmente fiel, de las doctrinas de su maestro. ${ }^{\text {II }}$

\section{El itinerario aristotelico: rechazar para reformular y recuperar}

Aristóteles rechazó la inmediatez con que Platón recurre al Alma; pero recupera plenamente, como constructo y realidad, la función del Alma en su Física VIII y en su Metafisica XIII. Y es esta recuperación, bien razonada y enriquecedora de la doctrina de Platón, lo que convierte al Filósofo en el alter ego del Maestro, como ven en él los neoplatónicos, especialmente los antioquena. Como ya antes lo veía M. T. Cicerón, en tiempos de la primera recuperación de los escritos aristotélicos, en la Roma del s. I a.C. contemporáneamente con la "edición" de Andrónico de Rodas.

Ii De aquí nuestra constante deuda teconocida con I. Düring: Aristóteles. El fue para los años sesenta lo que W. Jaeger representó para los treinta. 
El gran vuelco doctrinal, la gran ruptura con Aristóteles pese a las aparentes reverencias ante una autoridad que está en boca de todos, la inician los medievales del siglo XII, la culminan los del XIII y comienzan a reconocerla los del XIV.

\section{El arjé-télos es una exigencia lógica del concepto de continuo $y$ es dador de realidad óntica}

Pero ¿de donde surgió un tal arjé, que, a su vez, los medievales abandonan? Como tema que flotaba en el ambiente platónico-aristotélico, es una herencia de los presocráticos. Pero como una pieza, como tantas otras, bien reformulada por Aristóteles, el arjé es en primer lugar una exigencia lógica del concepto de continuo (Phys. VIII), antes que una realidad motriz de la fisica (Met. XIII).

Una vez asentado lógicamente, y mediante la inversión que ocasiona el propio arjé lógico en toda la extensión del discurso semiótico del Filósofo, surge el arjé fundamentador del movimiento. Es en este momento cuando Aristóteles reasume la tesis platónica del Alma cósmica en su nueva dimensión, el "noésis noéseos, $z 00 e^{\prime \prime}$. El tercer elemento, el zooé, vida, es también el tercer elemento de la terna platónica, el Alma cósmica, con mucha mayor proximidad y semejanza que los otros dos para el Bien y para el Demiurgo.

El more geometrico - pero generativo y no axiomático - del Aristóteles semiótico ocasiona, a la vez y en un juego cruzado de dialécticas, el momento estático del continuo, el momento dinámico del motor de la unificación y división, y el realismo de la entidad noética del arjé, doblándose en la terna de arjé - physis télos, y redoblándose en la terna modal definitiva de un "noésis noéseos, zooé" continuo.

Se trata de una estructura compleja y dificil en la lógica de una exposición diacrónica, a dos milenios de distancia; sin embargo debió ser mucho más espontánea y elemental en su momento y en un ambiente indoeuropeo, propenso a los juegos ternarios dialectizados, tanto como el semita lo es a las reiteraciones, compensadas dinámicamente por la autonomia de la acción verbal aparentemente sin sujeto. ${ }^{2}$

Recorramos brevemente este itinerario complejisimo acentuando únicamente aquello que es relevante para un modelo que permita comprender el paso desde Grecia hasta mediados del s. XIV.

\section{La triada del continuo (synechés) propiamente no es ni óntica ni lógica}

La locución humana no tiene un único nivel. Muchas de las piezas de un discurso concreto son indicaciones, seriaciones, reglas, códigos, definiciones (inevitablemente recursivas) y pautas de uso de otros signos del discurso u otros discursos inferiores, inmanentes al discurso global.

\footnotetext{
"Remitirlamos a los estudios de G. Dumezil para las ternas indoeuropeas (paradigmático wu Les dieux des Indo-europdens. Paris, PUF, 1962, ilustrado en variadas vertientes por la extensa produccion del gran "pre-estructuralista" francls, anterior y poeterior a estas cuatro conferencias) y a las tesis de Ems von Dobschütz: Zeit und Raum im Denken des Urschristentums, en "joumal of Biblical Literature" 41 (1922) 212 ss.; Thorleif Boman: Das hebräische Denken im Vergleich mit dem Griechischen. 1954 (esp. cap IV), para la comparacion de las estructuras lingüisticas indoeuropeas con las semiticas.
} 
La triada del continuo (synechés: división, unificación, lo mismo) propiamente no es ni óntica ni lógica, está dentro pero en oposición: es la condición primera, necesaria y suficiente, de la epifania del gran discurso coherente de la Physis, como unificación de divisos y división de unidades. Es la parte constituyente, pero no constitutiva, del fuego semiótico del discurso de la Physis, como el punto, el ahora, y el momento son los signos constituyentes, y no constitutivos, de cada modo fenomenológico del continuo.

En el siglo veinte diremos - sobre todo, es el "decir", lo que "se dice de muchas maneras" válida y licitamente - que el continuo y sus modos fenomenológicos son "funciones constitutivas" de la realidad en el discurso. Por ello, son algo metalingüístico, pero inmanente al conjunto semítico del discurso global. Como lo son las funciones constitutivas de la "geometría generativa" de los tres modos de la Physis: punto, ahora y momento. En absoluto, ninguna de estas funciones son "partes constituyentes" del discurso de nivel primero acerca de los "estos", "objetivados" necesariamente como singulares en la pragmática textual.

Pero Aristóteles no era del siglo XX. Tiene clara consciencia del carácter de "discurso funcional" que presenta su esfuerzo por hacer coherente y razonable con el continuo la enorme riqueza fenomenológica de la Physis real, tal como aparece ante la mirada de los autores de unos discursos valiosos sobre ella.

Tampoco Aristóteles es un mecanicista a secas, un empirista a secas. Porque tiene consciencia lingüistica y no cientifico-mecanicista, el Filósofo busca y halla un discurso funcional para que, sobre una base única y anchisima, "el unificar y el dividir sean lo mismo y respecto a lo mismo". Obtener esta identidad es la función de todo el discurso de la Fisica, es su tratado sobre la realidad.

\section{La aportación de Aristóteles a la doctrina de su Maestro: el méthodos}

Aristóteles, sin embargo, todavia es demasiado "primitivo" para poder separar en exceso "pensamiento" y "realidad". Como Platón, antes y con mayor facilidad separará tajantemente el duo "pensamiento y realidad" del duo del "lenguaje y la escritura". Así surgirá que, sobre la base del arjé como pensamiento que vive pensándose, lo que para el son discursos funcionales inteligentemente útiles, se convierten en, también, útiles y reales en el Pensamiento - arjé - real.

El continuo y su triple faenómenon son muy reales, pero no propiamente en la Physis, sino en el meollo inmanente de la pre-physis, en la constitución de la "corteza del Alma" que es la Physis vista ya desde el Télos, este Telos que unifica los fenómenos explicados por los discursos humanos parciales en el gran Zoón eudaimón omnicomprensivo y noético.

Esta es la aportación enriquecedora de Aristóteles a la doctrina de su maestro: el méthodos para poder afirmar, sin inconsistencia, la unidad del movimiento de la Physis atribuido acertadamente a un Alma. Y por esta razón, Aristóteles es el gran inspirador del Neoplatonismo, a la par del Aureo. Uno trazó lo genial, el otro genialmente halló el méthodos para los trazos geniales. 


\section{El meollo inmanente de la pre-physis, en la constitución de la Physis}

Pero avancemos paso a paso, una vez explicitado el efecto final de la substitución de la triada platónica por el noésis noéseos, zooé.

Al continuo le acontece lo mismo que al Alma platónica a juicio del Estagirita, y aún peor: el Alma cósmica podia interpretarse que era una realidad, una entidad en la Physis; el continuo es un constructo mental que tal vez, ni por equivocación, puede presuponerse real pese a su dialéctica, y precisamente por ella.

El continuo, pensado en vistas a reducir la multitud de paradojas del movimiento de la Physis, se basa en la identidad de la división y la unión. Pero esto genera una dualidad de actual y potencial que es pensable quizás, pero que no es autoconstituyente en ningún caso, si sólo es pensado: en ningún caso es la parte moviente y la parte movida. Precisamente la posibilidad de cisuras, o la posibilldad de identificacion entre cisuras, exige necesariamente algo que actualice esta potencia. La noción de continuo no sólo no explica el movimiento esencial de la Physis, sino que lo detiene de forma aún más inexcusablemente que el más abstracto, o concreto pero fijo, de los arjai presocráticos:

\section{El continuo y la presencia o ausencia de cisuras en la Physis}

Lo que sí impone con claridad la formulación del concepto de continuo tal como lo ha presentado Aristóteles, es la necesidad de explicar la presencia y ausencia de cisuras en la Physis. Y una realidad no se fundamenta ónticamente, causalmente, en una elucubración. Las palabras "narran" la realidad, pero no la causan, pese a todas las miticas sobre el Logos, Vac, Palabra y similares. Lo que puede unificar discursos humanos y hacerlos razonablemente complementarios, no crea la realidad que los discursos tienen por objeto.

\section{El continuo, su bifronte potencia de unión o división, y el motor inmóvil}

El mismo concepto de continuo, con su bifronte potencia de unión o división, impone lógicamente, por pura exigencia interna discursiva, una causa externa de la actualización de una u otra de las direcciónes potenciales. Evidentemente, la causa externa que establece la dual polaridad del continuo y su identidad de fondo es el pensamiento. Y, con no menor evidencia, la causa externa de la afirmación o negación de una u otra dirección radica en el objeto concreto y singular del conocimiento concreto.

En este punto Aristóteles ha alcanzado el meollo fáctico, y ya inicial, de su epistemologia, expresado en el "todos decimos" como patencia de un fenómeno determinado y real de la Physis. Bl pensamiento siempre tiene un "motor" que lo actualiza con tal o cual conocimiento y, ciertamente, un motor inmóvil: el objeto.

Si no se trata de un ente inteligente que aspire voluntariamente a hacerse conocer por otra mente - aprovechar este filón del trato entre entidades inteligentes, va a ser la característica del neoplatonismo cristiano, frente al pagano de la Physis - el objeto del conocimiento, en principio, es absolutamente indiferente al hecho del conocimiento, de ser conocido. El objeto de conocimiento atrae hacia sí al conocimiento como fin del conocer, pero en nada cambia él, ni nada ha de actua- 
lizarse, para que actue el objeto como fin. Ni nada será actualizado en el objeto al ser conocido. Una acción noética es intrínsecamente finalista del sujeto noético, no extrínsecamente, tan necesariamente como ser fin o motor inmóvil no es una caracteristica positiva esencial e inmanente del objeto conocido.

\section{La "geometria generativa", una espacialización inicial del continuo}

Conocer es permitir que un objeto imponga al sujeto los limites propios, que imponga las cisuras que fragmenten un continuo más ámplio. Para Aristóteles el continuo siempre será lógicamente anterior a la fragmentación. Y lo que fue imagen para nosotros más evidente y primera - la composición del continuo por identificación de límites en una "geometria generativa", una espacialización inicial que pasa de lo múltiple al unificado continuo - en la realidad objetiva será una acción segunda, la acción de recuperar la unidad inicial, el retomo de lo inteligente uno a su propia esencia, telos único del arjé noético único, después de desplegar la rica pluralidad de la Physis entre uno y otro término.

Y entonces si, como efecto del retomo de lo inteligente autointeligible a su esencial unidad, después de desplegar todas sus virtualidades, al reencontrarse el arjé como telos cumplido, aparece ante sí mismo como acción de conocer real, y como Motor Primero Inmóvil: surge el noésis noéseos, zooé. Surge la Intelección de la Intelección que, en esta acción de espejearse y auto determinarse como telos motor, ya es Vida, y ciertamente vida eterna, una vida no sucesiva, sino total en un ahora extratemporal.

\section{La Vida (Zooé) en el Alma (Psijé), plenitud y fin del Todo, fundamento de la Physis}

Este telos, acción vital eternamente cumplida de inteligirse como acción y como cumplimiento final, será el Motor Inmóvil Primero, causa real de una Physis real. Será no sólo motor inmóvil noético y lógico de la unificación o división de un continuo mental, sino Motor Inmóvil Primero físico de la totalidad real unificada en el telos de la Physis.

A la postre, se habrá cumplido el fllosofema de Platón, pero una vez plenamente desarrollado el proceso, no inicialmente: la fundamentación del movimiento, este movimiento que es esencial constitutivo de la Physis, está en la Vida (Zooé), en el Alma (Psijé), en el Espíritu (Anemos), plenos y final del Todo. Un Todo que, si aparece fraccionado en los discursos que "todos decimos", en realidad está y aparece fundamentado porque el fin único ya rige el comienzo, determinando, midiendo y numerando en concreto, como causa final, el desarrollo de su activa plenitud de Vida noética, que retoma sobre sí esencialmente, como acción de "Inteligencia" con retorno completo.

Y será verdad, ya desde Platón y Aristóteles, que asi como el arjé-telos es un acto de trina modalidad, también es verdad que la expansión expresiva, desde donde se recoge nuevamente en unidad expresada, es la "corteza del Alma" eterna, pero ya en la temporalidad y la corporeidad del movimiento local. Asi, con sus propios matices, lo entienden Plotino, Proclo y la abreviatio de Proclo en el ambiente damasceno del s. IX y traducido al latín en Toledo en el s. XII, el Liber de Causis. 


\section{Aquella misteriosa Fisica de Aristóteles...}

En la primera parte de este trabajo se intentó esbozar el punto de partida inicial de Aristóteles. Se lo describía como una epistemología semiótica a la que únicamente faltaba la consciencia de sí misma para que el Filósofo poseyera, en aquel entonces remoto, la misma definición que hoy cabría hacer de una tal epistemologia. El texto de los Soph. El. 165a 6-13 sirvió de base para comprender los primeros pasos teóricos de Aristóteles.

Comencemos esta segunda parte con una intuición, que nos parece muy certera, de I. Düring en su gran estudio de 1966: la Fisica de Aristóteles no era en verdad la consideración de la Naturaleza entera bajo el punto de vista de las cuatro causas. Esta hermenéutica "tradicional" tuvo su momento y su lugar."

\section{$Y$, sin embargo, Aristóteles no es un físico mecanicista ni post mecanicista}

Cuando I. Düring presenta su propia lectura de la Física aristotélica, también descubre su concepción de la Fisica de hoy con una pulcra explicitación muy loable. Y aquí surge la paradoja:

"Según la concepción moderna, la tarea de la fisica teórica consiste en descifrar partiendo del material de la experiencia nexcs de la mayor significación posible. Esta era también para Aristóteles la tarea de la física. La diferencia entre la fisica térica moderna y la suya consiste en que su material de experiencia era mucho más escaso; la fisica experimental le era aún completamente desconocida y no formulaba sus tesis matemáticamente" (p. 465).

Mucho nos tememos que la formación cientifica de Düring le ha jugado una mala pasada: por suerte o por desgracia, Aristóteles nunca fue un Newton menor o más primitivo. No hay la menor continuidad relevante, para nosotros, a finales del siglo XX, entre el griego y el inglés, el clásico y el científico. Y quizás el propio Düring lo sabia, a tenor del elenco de personalidades de la fisica post mecanicista que aduce en las páginas $466-67,{ }^{3}$ buscando una salida a las diferencias.

2 Bl sabio profesor de Heldelberg no duda en tildarla de "completamente falsa" (p. 464); sin embargo, semióticamente sólo puede calificarse de fructuosa y razonable para que los pensadores de un periodo histórico afrontaran eficazmente su presente.

* "Este tipo de materialismo, empero, sufrib un grave golpe en nuestro tiempo. Bl pensamiento a base de modelos dejo atrás su mejor época. La distinción cartesiana entre res extensa y mens, entre el proceso objetivo en el espacio y en el tiempo, por un lado, y el alma en la que se refleja este proceso por el otro, ya no es hoy dia el punto de partida de las ciencias naturales. Cuando el cientifico observa y describe los procesos naturales no es como lo formulo Niels Bohr solamente espectador, sino también actor en el espectáculo de la naturaleza. Los conocimientos que adquirimos sobre la naturalezs se llevan a efecto siempre en virtud de nuestra forma de proguntar. Entre nosotros y lo que antes se lamaba la tealidad objetiva está siempre nuestro planteamiento de la cuestión. La imagen de la naturaleza de la fisica exacta de nuestra época, dice Heisenberg, no es ya una imagen de la naturaleza. El objoto de la investigación ya no es la naturaleza en si, sino la naturaleza expuesta a la interrogación humana // Esta concepción del objeto de la investigación física es en principio afin a la de Aristóteles. Con su tesis de que en cierto sentido nuestro pensamiento es todo 


\section{En Aristóteles no existe la oposición moderna entre objetividad y subjetividad}

En efecto, como asegura Düring, era un error achacar a Aristóteles la oposición "objetividad / subjetividad". " Pero en los años sesenta no estaba nada claro cómo podian formularse unos discursos en donde todavia no aparecía la oposición, sobre todo porque no se adivinaba, de manera suficientemente generalizada, $\infty 6$ mo podia desterrarse la dualidad del discurso de los propios años sesenta. Faltaba la base común para un modelo realmente histórico que vinculara los tres tipos de discurso: el anterior a la Modernidad, el de la Modernidad, con la dicotomla de sujeto y objeto, y el de la superación de la oposición, con la posibilidad de entender de otra manera a los clásicos y a los modernos.

La epistemología semiótica era esta base común, cuya ausencia en una fórmula clara por aquel entonces, dejaba en una situación vacilante a nuestro admirado hermeneuta sueco.

\section{El objeto de la investigación ya no es la naturaleza en si}

Düring tiene dos observaciones que son un buen punto de partida para esta parte del presente trabajo: "El objeto de la investigación ya no es la naturaleza en si, sino la naturaleza expuesta a la interrogación humana." (p. 467) y "La genialidad estriba en la combinación de las funciones" (idem).

Para Düring la primera frase es un buen resumen de la epistemologia de la ciencia post mecanicista. En realidad, ya Ockham hace exactamente posible esto, y esto es la base de la ciencia mecánica, con sus modelos matemático algebraicos, a los que se refiere probablemente el autor sueco asegurando sin matices que "el pensamiento a base de modelos dejó atrás su mejor época" (p. 466).

Pero como que en realidad el pensamiento humano - lo supiera o no el hombre - siempre y en todas las latitudes ha funcionado a base de "modelos", lo que resulta genial en Düring es asegurar que en Aristóteles "La genialidad estriba en la combinación de las funciones".

Aristóteles combina las funciones semióticas genialmente $y$, hasta cierto punto, sin tematizarlo como hoy, es consciente de ello en la parte inicial de su especulación. Trabaja con funciones semióticas: entre la constatación de la pluralidad irreductible de los discursos hasta el descubrimiento de la omnipresencia de los motores inmóviles ante todo intelecto y la construcción de su Motor Inmóvil Primero. Pero precisamente combinando "funciones" con genialidad, Ockham adquiere consciencia de que pensar y hacer ciencia tienen como "objeto de la investigación ya no [es] la naturaleza en si, sino la naturaleza expuesta a la interrogación humana".

1o que exdste, traza con sobriedad los limitos de nuestro conocimiento. Como Wieland observa correctamente, es un error hablar en ese contexto de subjetividad u abjetividad, pues esta distincion no es hecha en abeoluto por Aristóteles,"

Como obeerva acertadamente During, haciendose eco de W. Wieland, en la p. 467, o bien advirtiendo, en la pagina anterior, que para Aristóteles "el movimiento existe independiente de nuestra percepción" y que "no tiene sentido preguntar que son las cosas en si, pues nuestro pensamiento "es' en cierta forma todo lo que exdiste" (p. 466). 
En lo único que difieren - Aristóteles, Ockham y cualquier vecino - es en el dónde, cuándo, cómo y para qué se combinan unas "funciones". Unas funciones que, salvo algunos aumentos cuantitativos, son materialmente las mismas o materialmente similares en Grecia, en la Edad Media e, incluso, hoy.

Y, sin embargo, precisamente por el "dónde y cuándo" (historia), por el "para qué" (finalidad intelectual, en el imaginaire o en la pragmática real en la época) y por el "cómo" (limites del mundo semiótico disponible y toponimia formal de los signos establecida por el uso en el discurso), las tales "funciones" semióticolingüisticas difieren sensiblemente de uno en otro autor, de una en otra generación, de un en otro periodo histórico.

\section{La genialidad estriba en la combinación de las funciones}

En el caso que nos ocupa, Aristóteles se muestra genial, refuncionalizando los términos heredados de sus antecesores hasta su inmediato Platón, para establecor la unidad dialéctica del conjunto de los plurales discurso que "todos decimos". Ockham con genialidad retoma los términos aristotélicos para aplicarles una especie de "medicina lógica del lenguaje" que cure los abusos de los moderni y los dislates del hombre de la calle a raiz de la doctrina aristotélica.

La genialidad del Inceptor es reducir la multitud de funciones de los signos que "se dicen - por parte de todos - de muchas maneras" a una única manera correcta. Una única manera que, además, ya es conscientemente una función lingüistica muy determinada hacia un bien concreto uso, en un bien circunscrito mundo del discurso; y una función que prescinde en absoluto de qué cosa sea en sí el objeto del conocimiento "cientifico", "pericial" y no de la calle.

Siempre el objeto del conocer cientifico será meramente fáctico y a la luz de un fin. El conocimiento "objetivo" será, para el Inceptor, universal y necesario sólo por la disposición formal logica del discurso, y no por una disposición formal semiótica. Con un evidente reduccionismo de la riqueza de la construcción semiótica, Ockham ignora este ámbito formal constitutivo del juego semiótico - que en Aristóteles, con su "todos decimos", todavia era primordial - para quedarse normativamente en un empobrecido formalismo lógico "natural": queda Ockham en cómo "todos deben" vincular los términos relevantes, intuitivos y meramente denotativos de un "esto" real. No hacerlo así, para él es errar, pura y simplemente. Para el medieval nunca será un afirmar o negar dialéctica y fácticamente lo diferente y complementario, según es propio de Aristóteles, en vistas a la unificación de los discursos que "todos decimos".

* Expresión que adoptamos del contexto del analisis del lenguaje para caracterizar la posición que toma Ockham en textos bastante comunes como: "Et ideo omnes propositiones sonantes, quod puncta sint diversa res, et quod instantia sint diversa et sint distinctae res a tempore et a motu et a rebus permanentibus, exponendae sunt ad istum intellectum verum." (Suc. III, p. 109 c.f. ctr. paralelos: Succ. p. 42, 48). "Et ideo semper tales orationes exponendae sunt modo praedicto vel aliquo alio modo conventiori, si inveniatur, quis sufficit mihi, quod praeter res permanentes presentes, praeteritas et futuras non sit aliqua alia res distincta." (Succ. II, p. 61). 
Bs dificil encontrar dos combinaciones geniales de funciones tan antitéticas. Una da en la estupenda riqueza de una asimilación unitaria y razonada de todos los matices del lenguaje de la calle, de los discursos del hombre normal, aquellos que cierto consensus omnium exija y garantice. ${ }^{n}$ La otra convierte reductivamente las tres grandes áreas del discurso humano ordinario sobre la realidad - movimiento o vida, espacio y tiempo, con mil "enciclopedias" cada una de ellas - en la definición lógica de tres variables unívocas, aptas para su inclusión en algoritmos destinados al cálculo. Las del Inceptor ya son las mismas variables de movimiento, espacio y tiempo que Newton acabará de matizar y distinguir con sus conceptos de masa, gravedad, y velocidad, para vincularlas en su dinámica de sólidos.

Aventuremos, pués, de entrada, que Ockham menciona con clarividencia, sin usarla, una dimensión semiótica que Aristóteles, sin hacer mención de ella, usa con enorme fuerza y capacidad. Aristóteles es un gran filósofo que piensa totalidades del Todo; Ockham es un espléndido epistemólogo cientifico, como lo pedia y permitia el siglo XIV, que acota ciencias particulares irreductibles a una totalidad.

\section{Concepto de ciencia física en Ockham: discurso util sobre lo real}

Bn efecto, Ockham escribe un tratado universitario de "Física", cuatro para una mayor exactitud." Para Guillermo de Ockham - sin tamizaciones, como la "intencionalidad" conceptual de Tomás - una ciencia "real" es un conjunto de proposiciones acerca de la "realidad" presentes en la mente del cientifico a la manera de un habitus."

n $\mathrm{Y}$ sin que la mente las relativice y compatibalice, aplicando lo que Düring destaca múltiples veces (v.gr.: pps. 133 y 219), la argumentación "in utramque parte dicendo", una operación que, en latín tal como la cita el protesor heidelbergiano - $y$ literalmente, parece extralda de Clcerb́n con exquisita fidelidad (Académica II, 3 (7); De Orat. III, 80; De Fin. V, 10; v6ase el comentario de During en la nota 59 de la p. 219). En realidad se remonta a los TCpicos de Aristóteles (VIII, 13, 163b 1-15). Nótese que no son un ejercicio escéptico tales argumentaciones, ni en el Filosofo ni en el Cónsul, sino un ejercicio de humildad profundamente humano, exigido por otro principto aristotelico y ciceroniano: "cada uno aporta algo propio a la verdad" (Etica eudemia I, 6, 1216b 26-33; Cfr. Düring, L.: Aristóteles, pps. 47, 61, 626, 710, 771). Y unas prácticas que aconseja Aristóteles, el Lector, en To. picos I, 14, $105 \mathrm{a} 35$-106b 19, esp. 12-19: " Es útil también escogyet de entre los argumentos escritos, y confeccionar listas de cada clase,..." (Trad. M. Candel en Aristoteles: Tratados de Lógica (Organón), Vol. L., Madrid, 1982, p. 110).

Guillelmi de Ockham: Bxpasitio in Mbros Physiconum Aristotelis. (vols. IV-V; abreviaremos Exp.); Summula Philcosphia Naturalis (vol. VI: abtev. Ph.N.) y Ouaestianes in libros Physicorum Aristotells. (Vol. VI, abtev. Quaest) de las Opera Philosophica et Theologica. Opera Philosophica. Institutus Franciscanus Universitatis Sancti Bonaventurae, St. Bonaventura (N.Y), 1985-87. Además, Guillelmi de Ockharn: Tractatus de Succesivis. En Böhner, Ph. The Tractaus de Succesivis' artubuted to William of Ockham. Editet with a Studl on Life and Works of Ockham. St. Bonaventure (N.Y). St. Bonaventure Univ., The Franciscan Institute.1944.

* Para los conceptos fundamentales acerca de qué es ciencia, sus causas su unidad, su sujeto y objeto es imprescindible el Proemium a la Exp., o.c.y los Praeambula de la Ph. $N$. 
Ahora bien, en el pensamiento de Ockham, una proposición no tiene absolutamente ningún origen causal inmediato en el mundo extra mental, o intra subjetivo. ${ }^{*}$ Una proposición simplemente es una operación logica, formal, que vincula entre si dos vivencias ${ }^{21}$ sobre el mundo, ya presentes en el espiritu del sujeto" atómicas y vacias de contenido noético - unas vivencias que hasta aquel momento habian permanecido aisladas, pero que con alguna finalidad concreta el sujeto relaciona en un momento dado y juzga la relación mental establecida entre ellas para asignarles un valor de verdad o falsedad, que resulta informativo en ambos casos.

Muy aristotélicamente, tal vez y, en todo caso, muy consecuentemente con

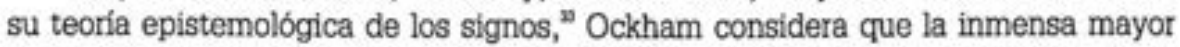
parte de las proposiciones de la ciencia fisica son experimentales: fruto de la interrogación de la realidad por parte de un intelecto que tiende no sólo hacia su reposo natural en el acto de conocimiento, sino hacia la solución del problema de cómo obtener un fin.

* I Sent. Prologus, q.1,a.1, concl. 3(OTh.J, 22,3-15. Ctr. tambièn D.3, a.6 (OTh. II, 506 ss.) y Quodl. (OTh. IX, 86, 68-73).

a "Vivencia" en cuanto el signo es vacio, atómico y pre-cognoscitivo categorialmente. El paso de vivencia primera a "signo lingüistico" es laborioso, pero no categorial, todavia, sino "eecuivalenter" a un proceso categorial de predicación. Signum: "Hoc est X": "ac si", "iudicium aequivalenter": I Sent., Prologus. q.1, a.6 (OTh. I, 69,22 - 70,2) - Intuicion / abstraccion y Concteto / abstracto: "idem totalitet et sub omni eadem ratione", cfr. I Sent. Prologus, q.1, a.1 (OTh. I, 30,5-39,16).Universal: "natura oculte procedit": I Sent. D.II, q.7 (OTh. II, 261,13-20).

Conocer en Ockham es una acción del espiritu subjetivo libse, no asl la inteligencia, que es puramente pasiva de la "realidad". Vide nuestro Fortuny, F.J.: La Ontologia del espiritu: principio de epistemalogia de G.Ockham. Convivium. Barcelona 1990.

Reducimos a una brevisima nota el meollo de la epistemologia de Ockham, con sus textos relevantes: 1. - Argumento - proposición - término- Término: oral, escrito, mental; no jerarquizados. Naturaliter / voluntarie. Logica Maior. I, 1 para los tres apartados. SICNUM: agustiniano / linguíistico: Logica Major. I, 1, lins, 53-65. Rasgos del signum - Vacuidad del signo (ni imago ni vestigium): Fortuny, F.J.: Naturalldad y vacuidad del signo en G. do Ockham. Bn "Paraula 1 historia. Miscelánea P.Basili de Rubi". (Ed. F. Raurell), Barcelona, 1986, pp. 535-569. - Realismo atomistico de Ockham (no "nominalismo").- Inseparabilidad del espiritu y el mundo 7: inturición del no-existente: I Sent., Pralogus, q.1, a.6 (OTh. L. esp. 70,21 - 71,9). Cfr. Quodi. (OTh. IX, esp. pp. 76-77, 498 s., 604). 2Qujd sit signum? Definicion ontológyica: Logica Maior 1, 12, lins. 29-47: "Sed quid est Illud in anima, quod est tale signum? Dicendum, quod circa istum articulum diversae sunt opiniones.Aliqui dicunt, quod non est nisi quoddam fictum per animam. Alii, quod est quaedam qualitas subiective existens in anima distincta ab actu intolligendi.Ali dicunt, quod est actus intelligendi. Bt pro istis est ratio ista, quia frustra fit per plura, quod posest fieri per pauciota. Omnia autem, quae saivantur ponendo aliquid distinctum ab actu intelligend, possunt salvarl sine tall distincto, eo quod 'supponere' pro allo et 'significare' aliud ita potest competere actuf intelligendi sicut alli signo. Igitur praeter actum intelligendi non oportet aliquid aliud ponere." - fictum: "opinio ab autote olim proposita": 1 Sent. D. $2^{2}$, q. $8^{2}$ (OTh. I, p. 271,13-272, 19)- qualitas mentis-- ipsarnet intellectio: "opinio posterior auctoris": I Sent. D. 20, q. 8 (OTh. 289, 11-291,15). Nulla species: I Sent. D. II, q. 8 (OTh. II, 269, 1-16). 3. - Definicton funcional del signo: Significare: "Hoc est X": Logica Major I, 33. - Supponere: Logica Maior 1, 63-77. - Suppositio propia: simplex: Logica Major 1, 64, lins. 27-38; 68 passim-- materialis: Idem lins. 39-44; c. 67 passim,- personalis.. Idem lins. 3-8; cc. 69-74.- Suppositio impropia (Polémica Paris, 1340|: Logica Maior I, 77. 


\section{La finalidad intencional de la mente humana es prevalente en la teoría de Ockham}

Lo importante es que para Ockham no sólo incide en el acto de conocimiento la finalidad "natural" de la inteligencia humana, sino la finalidad intencional del espiritu, su objetivo explícito. Es prevalente y determinante, en la teoria de Ockham la finalidad intencional.

Ockham es consciente de que, al considerar nulo el protagonismo de las cosas reales en el establecimiento de las proposiciones, no sólo no habrá de buscar en la "naturaleza" - es decir, en una Physis con principios inteligentes, como la griega - una imposible universalidad y necesidad, sino que, además, no podrá confiar en la armonia y unificación necesaria del conocimiento por imposición del objeto. Y el Inceptor no lo espera ciertamente, tras proclamar la hegemonia de los fines intencionales por encima de los naturales. No sólo los cuerpos carecerán de un lugar natural en Ockham; tampoco lo poseerá la mente.

\section{Collectione multorum habituum ordinem determinatum et certum habentium}

Ockham no dice ni puede afirmar que la mente "crea" o "construye" el objeto de la ciencia a efectos epistemológicos; pero, pese a su realismo, ya está dando pasos hacia ello. De momento si afirma, y muy claramente, que la "ciencia" propia de una "facultad" universitaria es un conjunto fáctico de proposiciones

"[...] aliquando accipitur pro collectione multonum habituum ordinem determinatum et certum habentium. Bt isto secundo modo accipitur scientia frequenter a Philosopho. Et scientia isto modo comprehendit tamquam partes aliquo modo integrales habitus principiorum et conclusionum, notitias terminorum, reprobationes falsorum argumentorum et errorum, et solutiones eorum. Et sic dicitur metaphysica esse scientia et naturalis philosophia esse scientia, et ita de aliis.

Tertio ex istis eliciendae sunt aliquae conclusiones. Prima est quod metaphysica, similiter mathematica et philosophia naturalis, non est una scientia secundum numerum illo modo quo haec albedo est una numero et iste calor et iste homo et iste asinus" (Exp. Proemium, 2, lin. 55-3, lin. 5; ctr. Ph.N. Praeambula, lin. 23-77).

La ciencia, como conocimientos propios de una Facultad y normalmente recluibles en lo que nosotros denominariamos tratado o manual, para Ockham son una multitud de hábitos cualitativos de la mente con una unidad muy laxa. La unidad que corresponde, por ejemplo, a noticias tan dispares como es la propia doctrina y el rechazo de las sententiae de otros maestros.Y, sin embargo, la ciencia tiene "ordo determinatum et certum".

"Ideo dicendum est quod metaphysica non est una scientia numero, nec similiter philosophia naturalis, sed philosophia naturalis est collectio multorum habituum, sicut dictum est. Nec est aliter una, nisi sicut civitas dicitur una vel populus dicitur unus vel exercitus comprehendens homines et equos et cetera necessaria dicitur unus vel sicut regnum dicitur unum vel sicut universitas dicitur una vel sicut mundus dicitur unus" (Exp. Proemium, - 3, lin. 23-29; id Ph.N.). 
El "ordo determinatum et certum" que corresponde, en definitiva, a una finalidad y un centro de interés humano. No tiene la ciencia otras causas, efectivamente, que la causa eficiente - el cientifico - y la causa final ${ }^{\mathrm{x}}$ - la intención por la cual el cientifico busca un determinado conocimiento. La ciencia es una qualitas mentis de tipo habitus que cumple la regla general de los accidentes: esse ab alio $e$ in alio, y, lógicamente, carecer de causa material y, con mayor razón, de causa formal. Nunca un accidente puede romper la cerrada unidad de un ente singular, según el principio de los trascendentales, "omne ens, unum".

La unidad de la ciencia, una unidad que emanaba de la finalidad eficiente del científico, es explicitamente separada incluso de sus elementos formales. Una ciencia no tiene un "sujeto" único, si por sujeto ha de entenderse aquello de quien algo se sabe (idem, 3, lin. 76). Habra muchos "sujetos" proposicionales en una ciencia, y ello aún que se reconozca alguna primacia a un sujeto, por su excelencia, por sus funciones de totalización, etc. (idem 3, 103-120).

\section{Non sunt introducta nisi causa brevitatis loquendi vel ornatus locutionis}

Y aún ahonda más el Venerabilis Inceptor y, con ello da la definitiva vuelta de tuerca a una teoría epistemológica que no puede ser más opuesta a la de Aristóteles y a la de los clásicos en general:

"Dicendum est, quod talia nomina, quae descendunt a verbis et etiam nomina descendentia ab adverbis, coniunctionibus, praepositionibus necnon et a syncategorematibus, sive sint nomina syncategorematica, sive verba, sive quaecumque alia, sive alterius partis orationis, non sunt introducta nisi causa brevitatis loquendi vel ornatus locutionis, et multa eorum aequivalent complexis in significando, quando supponunt non pro illis, a quibus descendunt; et ideo non significant aliquas res praeter Illas, a quibus descendunt, et significata eorum. Hulusmodi autem nomina sunt omnia talia: negatio, privatio, conditio, perseitas, contingentia, universalitas, quantitas, quae dicitur quantitas propositionis, actio, passio, calefactio, frigefactio, mutatio, motus, et universaliter omnia nomina verbalia descendentia a varbis, quae sunt in praedicamentis agere et pati, et multa alia, de quibus modo non est pertractandum."

La mutación y el movimiento figuran en la lista, bien abundante, de verbos substantivados. Luego el buen franciscano, aplicará la misma reducción al espacio y al tiempo: a todo aquello que es sucesivo o es un continuo, "compuesto" de posibles sucesivos contiguos. En todas las obras fisicas, en cada parte de las tres del opúsculo cómodo del De Successivis, siempre y acentuadamente la cuestión primera es "motus, locus, tempus non est": estos sucesivos físicos no existen a la manera como se dan un hombre, un cuerpo o un calor.

\section{Exp. Prologus, 3 (O.Ph. IV. p. 7-8).}

La cita esta recogida de The tractatus de Successivis attributed to Willarn Ockham, Bditet by $\mathrm{Ph}$. Böhner. St. Bonaventure (N.Y), The Franciscan Institute, 1944; pág. 37. Pero el texto de repite en la pág. 97 de la obra, e, idéntico, en las Summulae Logicales sive Philosophia Naturalis, III, 4, líns, 2638; cfr. 3, lins. 1-19 y en otros varios lugares del Opera Philosophica. VI (cfr. Indices conceptuales: nomina). Se podria hablat con mucha propledad de la sanatio linguae o de la medicina linguistica aportada por Ockham. 


\section{Et dico, vestigiis Aristotelis inhaerendo, quod...}

\section{$\mathrm{Y}$ continua nuestro autor medieval:}

"Et quia talia nomina propter causas dictas sunt inventa, ideo multoties diversimode et aequivoce accipitur ab auctoribus in diversis locis" (De Succ. P. 38, pero véase págs. $56,59,100,117-119$ etc).

\section{Y en la Philosofia Naturalis incluso llega a afirmar:}

"Et dico, vestigiis Aristotelis inhaerendo, ${ }^{\text {" }}$ quod non sunt nobis talia vocabula necesaria ad exprimendum omnia quae de rebus quando mutantur concipimus. Propter quod talia vocabula 'mutatio', 'mutatum esse' et similia, quae faciunt difficultatem in istis rebus, non requiritur ad exprimendum conceptus nostros, sed sufficiunt ista: mutable, mutatum, mutandum, mutatur... Tales enim sermones sunt sane intelligendi, et ad videndum de veritate et falsitate eorum, resolvendi sunt in sermones proprios pro quibus ponuntur impropit" (S.Ph. o Ph.N. III, 3, 7-13, 17-19).

Mejor se diria - lo vímos ya más arrba - que Aristóteles procede exactamente de la manera contraria a la que sigue el Inceptor. Por lo contrario, Ockham consciente en hablar "como todos", pero no en pensar como todos." Aristóteles creyó que habian pocas palabras para decir la gran cantidad de cosas existentes," a Ockham le sobran palabras y reduce el discurso a unas pocas fórmulas, necesarias, breves y exactas. Ockham presenta esta reducción, verdaderamente severa, como la auténtica intentio Aristótelis" y como real "salvación" de cuánto los autores quieren obtener con su discurso fisico, sean fenómenos, sean funciones linguísticas.

an

Ockham no duda en asegurar que multas difficultates emergentes ex autoritatibus Phillosophorum male intoloctis.. (S.Ph. O Ph.N. III, 3, lins. 31-37). Como tampoco ve ninguna dificultad en el tema del tiempo, $\tan$ asequible a las personas sectllas, si la mente no se ofusca con malas intelecciones de ciertos fildsofos

n "Et revera simplices, qui imaginantur, quod sicut nomina distingruntur, ita semper correspondent distinctae res, res melius esset eis uti tali modo loquendo quam alio. Ouia tamen locuendo est ut plures, ideo volo uti consimili modo loquendi, numquarn tamen intelligo, quod ternpus sit aliquid unum secundum se totum distinctum ab omnibus rebus permanentibus. Sed per talem propositionem: tempus est, non est alliud intelligendum, nisi quod aliquid movetur, unde anima potest intelligere, quantum movetur allud (De succ. III, p. 100) Antes hernos aludido a una cierta "medicina del lenguaje" respecto a esta actitud.

* -... en efecto, los nombres y la cantidad de enunciados son limitados, mientras que los objetos son numéricamente infinitos. Bs pues necesario que un mismo enunciado y un ùnico nombre signifiquon varias cosas" ya citado supta, correspondiente al final del texto de Soph. EJ. 165a 6-13.

》ง La intentio Philoscphi es un tema recurrente en las obras físicas de Ockham. La voluntad de buscar la intentio del Estagirita ya figura en la segunda linea del De Successivis,pero este párrafo introductorio es de los fragmentos cuya autenticidad ockhamista es nula, obra del abreviator. Figura la intentio en las p. $35,50,51,52,53,69,73,77,80,97,91,99,102,114,115,119$. Sirva de muestra el texto de la p. 119-20 por lo que tiene de voluntad omnicomprensiva: " $\mathrm{Bt}$ ideo nota: Intentio Aristotelis in toto isto capitulo de tempore summatim locquendo est ista, quod tempus nec dicl aliquam rem distinctam extra animam, nisf quam significat hoc nomen motus primus, etsi forte connotet al.quid aliud, puta animam mensurantem vel natam mensurare; et quod motus primus non importat aliam rem nisi movile. Et tamen hoc non obstante de mobili praedicantur // diversae definitiones non synonymae, quamvis mobile secundum suam substantiam non sit diversum nec etiam allqua res sibi adveniat ipsum informans. Ita hoc nomen 'instans' sive hoc adverbium 'nunc' non importat aliquam rem distinctam secundum se totam, quae non importatur per hoc nomen 'moble'."

- Tampoco el concepto de "salvaction", salvare apparentis, salvare phaenomena, resulta indemne al pasar por el tamiz ockhamista de la intentio auctoris. Texto paradigmático puede ser el de De Succ. 


\section{Los tres grandes conceptos fisicos de Ockham}

Pero, en definitiva, ¿qué son los succesivos fisicos, movimiento, lugar o espacio y tiempo? ¿cómo o qué "salvan" las expresiones del filósofo medieval? No vamos a seguir el proceso discursivo de Ockham ni aún en su breve De Succesivis. La atención va a recaer especificamente en las definiciones estrictas de los sucesivos físicos, con el mínimo de contextualización que se exjja para evitar los equívocos.

\section{Para Ockham el movimiento es un proceso visto sólo desde la mente}

Ockham hace suya la noción de movimiento de Aristóteles y la reproduce una y otra vez en su versión latina: "motus est actus entis in potentia in quantum in potentia". El Inceptor asume con entusiasmo que el movimiento es un proceso.

Pero, de acuerdo con su epistemologia, la verdadera definición del movimiento en el filósofo franciscano es más "proposicional" que en Aristóteles. Observemos, sin embargo, que en verdad no resulta tan detonante la diferencia a los ojos de un lector normal, que no pueda este afirmar tranquilamente que no se dice nada especialmente diferente o nuevo. El lector normal lo proclamaria con la misma buena fe y seriedad con que Ockham cree restaurar la doctrina de los antiqui frente a las concesiones de los moderni contra la intentio Philosophi. En el De Succesivis escribe:

"Ideo dicendum est, quod motus non est talis res distincta se totam a re permanente, quia frustra fit pet plura, quod potest fieri per pauciora sed sine omni re tali possumus salvare motu et omnia quae dicuntur de motu; igitur talis res alla frustra ponitur. Quod autem sine tali re addita possumus salvare motum et omnia, quae dicuntur de motu, patet discurtendo per singulas partes motus.

De motu enim locali patet. Ponendo enim, quod corpus sit in uno loco et postea in alio loco, sic procedendo sine omni quiete et omni re media alia ab ipso corpore et ipso agente, quod movet, vere habemus motum localem; igitur frustra ponitur talis res alia.

Si dicatur, quod non sufficiunt ad motum localem corpus et locus, quia tunc quandocumque essent corpus et locus, tunc esset motus et ita corpus semper moveretur - dicendum, quod corpus et locus non sufficiunt ad hoc, quod motus sit, ita quod ista consequentia non est formalis: corpus et locus sunt, igitur motus est. Et tamen

I, p. 35: "Frustra fit per plura quod potest fieri per pauciora, sed... ergo propter mutationem salvandam frustra ponitur alia res a materia et forma et agente et cacteris rebus permanentibus" en donde el salvare está dominado por el "principio de economia". En el mismo sentido aparece en el mismo De Succ. p. 70. Respecto al tema del locus el sarvare aparece en el ámbito del "ac si" cfr. p. 81 y 87 y en la pdg. 91 viene a conjugrar la intentio autoris con la aequivalentia o el "per aequivalentiam". ¿Qué es lo que intenta salvar Ockham? Algo muy especifico, no la multoplicidad de "maneras de decir" del discurso de la calle. Pero habra de verse con las definiciones de los "sucesivos" físicos que el fin restan en vigor.

Bl abreviator de Ockham no duda en asumir en uno de sus escasos textos de enlace "Qula communis opinio est, quod motus, tempus et locus sint quaedam res aliae a mobili et locato, ideo quae sit intentio Philosophi et Commentatoris de hoc est videndum: et primo de motu, secundo de loco, tertio de tempore." (De Succ. p. 32). La contraposición antiqui / moderni es constante en las obcas especulativas o politicas de Ockham. Y él siempre se situia entre los antiqui frente a las novitates y lo realismos recientes. 
praeter corpos et locum non requiritur alia res, sed requiritur, quod corpus prius fuerit in uno loco, et postea in alio loco, et sic continue, ita quod numquam in toto lllo tempore quiescat in aliquo loco Bt patet, quod praeter omnia ista non ponitur alia res a rebus permanentibus" (p. 45).

La frase ponendo enim, quod corpus sit in uno loco et postea in alio loco, sic procedendo sine omni quiete et omni re media alia ab ipso corpore et ipso agente, quod movet, vere habemus motum localem, es la definición más propia del quid nominis del movimiento en Ockham. Nótese que es del quid nominis, ya que no otra definición cabe para lo que no es una entidad absoluta, un "esto". Y el "ponendo quod corpus sit in uno loco et postea in alio loco" es equivalente a la formula que se halla en otras obras "hace verdaderas de una forma sucesiva y sin interrupción dos frases contradictorias: ahora está aquí, ahora no está aquí". " Parece que escuchamos de nuevo "lo mismo..., pero su ser es diferente" con el lugar y el lugar para una única cosa. No hay tal.

Concorde con Aristóteles, al parecer, Ockham asegura que el cambio substancial no es movimiento, sino de una manera impropia o metafórica. $\mathrm{Bl}$ movimiento más propio es el local. Ciertamente algo de esto asegura Aristóteles al identificar movimiento con proceso ${ }^{\circ}$ y reconocer que muchas veces otros tipos de movimiento se hacen perceptibles bajo fenómenos de cambio local, por disposición de partes en el espacio.

Pero en cambió Ockham no habla precisamente como Aristóteles lo hace en el comienzo del libro III de la Fisica: "Puesto que la naturaleza es un principio del movimiento y del cambio, y nuestro estudio versa sobre la naturaleza..." ${ }^{\text {"n }}$ Las tres exposiciones sobre la Fisica aristotélica y la abreviatio del De Successivis ¿ hablan de he Physis aristotélica o tratan de los fenómenos comunes a las cosas físicas? Ya quedó dicho qué es la Fisica como manual universitario, cómo tal Fisica carece de un sujeto o un objeto o un fin propiamente dichos, cómo "el 'mundo' no existe, salvo que se aluda a un sujeto por totalización"."

e En Succ. III, pp. 108-109: Ya es reveladora la redaccion del texto sobre el "movimiento del clelo": Bt nihil aliud dicit Commentator, commento 100, quando dicit: 'Nos percipere tempus ex perceptione motus', etc. Vult dicere, quod non percipimus tempus praecise ex hoc, quod percipimus motum, in quo transmutamur, hoc est, motum coeli, in quo transmutamur, quia coexistimus illi motui. Sed accipimus determinatarn partem illius motus, hoc est, accipirmus, quod movetur a tall situ usque ad talern situm determinatum. Bt hoc erit, cum senserimus duo instantia, // cum primo dicimus: 'hoc mobile nunc est in $\mathrm{A}$ ' et postes dicimus: "hoc mobile nunc est in B'. Bt tamen postquam diximos: 'hoc mobile nunc est in A', et antequam vere diximus: 'hoc mobile nunc est in B', vere diximus: "hoc mobile movenur". Bt ita accipimus duo nunc et motum medium.

- Sobre la importancia del concepto de "proceso" en Aristóteles frente a Platón velase I. During: Aristóteles. p. 115, 379, 516 y 522 .

4. Phys. III, 1, 200b 12-14.

- Ph. N. Praeambula, lins. 79-188:La desaparición del arjé-telos platónico-aristotélico del área de la Fisica se produce en el s. XII con figuras como Guillermo de Conches y los chartrianos en general. Véase la magnifica sintesis de T. Gregory: Sapientia christiana, que ya habla sido precedida por el Anima Mundi. Del mismo autor y en el mismo ámbito del platonismo chartriano. 


\section{En el quid nominis del movimiento se da una dialéctica menor, ténue}

La Fisica de Ockham es una colección de proposiciones sobre la multitud de "estos" permanentes e individualizados a los que atiende un pequeño "esto" espiritual, subjetivo cognoscitivamente, que en su mente, y sólo aquí, relaciona extrinsecamente los "estos" que alcanza a definir.

El discurso físico del hombre en Ockham sigue apelando a la dialéctica ¿cómo hablar de movimiento sin ella? La fórmula clave de Aristóteles todavía vitaliza el pequeño discurso del movimiento al pedir este que la unidad de un movimiento surja de verificar sucesivamente y sin interrupción dos proposiciones contradictorias. Pero sólo en esta fórmulita definitoria del quid nominis del movimiento se da una dialéctica bastante pálida y débil, justo lo necesario y suficiente para describir un proceso mecánico.

No hay dialéctica luego, en el uso coordinado de los tres sucesivos fisicos; Ockham relaciona funciones lingüisticas con conectivas no dialécticas, sino algo. rítmicas. Si es así, prácticamente Ockham retrae la presencia de los movimientos dialécticos sólo al ámbito de la construcción de signos, del definir el quid nominis, no al de su uso discursivo en general.

Las ternas dialécticamente conjugadas son omnipresentes en Aristóteles, desde la de arjé-telos y Physis, a partir del noésis noéseos, zooé, hasta la terna de movimiento espacio-temporal en el mundo cotidiano del hombre. Movimiento, espacio, tiempo son en el Flósofo un reflejo, invertido en la reflexión, de la terna del arjé: la fenomenologia de la Physis proporciona en verdad unos movimientos en los que la reflexión descubre la oposición espacio-tiempo y, más atrás, la entidad, y remotamente la entidad global de la Physis una.

\section{Dualidades, frente a ternas, en el pensamiento y discurso de Ockham}

Todas estas ternas, dinamizadas por una relación dialéctica, desaparecen en Ockham, sacrificadas a dualidades como subjetividad/objetividad, entidad/discursos, dato empírico/formalidad, etc. Se está preparando el inminente paso a la dualidad "proceso/elementos calculables"; lo importante no será ya el movimiento procesual del todo que rige a la parte, ni tan sólo el propio movimiento procesual menor y singular, sino la capacidad mecanicista de dominar por cuantificación uno de los elementos constitutivos de algún proceso corpóreo, naturalmente con un resultado al margen del movimiento del proceso que hizo posible obtenerlo. Y ello en vistas a la utilización del dato en una sintesis especifi$\mathrm{ca}$, bien delimitada, definida por el hombre y sus necesidades, en vez de serlo por un todo cósmico o un todo divino.

\section{El tiempo: un momento real de la realidad, prévio a toda consideración humana, en Aristoteles}

Una reducción similar a la sufrida por el movimiento, afectará al espacio y al tiempo. Ockham no está situado en las mismas coordenadas semióticas de Aris- 
tóteles. Ontica y tendencialmente, el Estagirita "comparte" con, participa del mismísimo "discurso total" del Nous cósmico, idéntico al Todo "real". En la totalidad del universo de discurso de Aristóteles, participación limitada del Lógos, será más o menos dificil expresar la "realidad" del tiempo con palabras, pero el tiempo no es "ideal", como no lo son la "ideas" de las cosas, sino estructura real de la realidad en sí misma. El tiempo es un momento real de la realidad total, fuera y prévio a toda consideración humana.

El fundamento de los sucesivos físicas en Platón y en Aristóteles - con claras diferencias - es el Alma y, exactamente, el Alma y no la Inteligencia, como asentarán claramente los neoplatónicos: los sucesivos fisicos son y sólo se dan en la "corteza del Alma": son el "sensorium Dei", efectivamente, y no el divino Logos, como tampoco son el desencarnado espacio y tiempo ideales de Newton. En Platón, Aristóteles y los neoplatónicos la "geo-metría" es "geo-gonía", y no una teorización puramente mental humana y apriórica.

\section{El tiempo en Ockham:}

en y por la dualidad "dato empírico / estructura formal"

Todo lo contrario ocurre en Ockham. Y, precisamente porque casi ocurre todo lo contrario, la noción de tiempo de Ockham es sumamente ambigua: aparentemente más "real" que la aristotélica, pero proclamadamente sólo en y por el alma, un alma inequivocamente humana y singular. La pseudo-semiótica del Inceptor ancla su doctrina en la dualidad "dato experimental/estructura formal a prior" y genera las ambiguiedades del "mundo de la representación", en expresión más tardía.

En efecto, el tiempo para Ockham es un extraño producto de la subjetividad anclado en la experiencia. Todo el discurso unificador de Aristóteles sobre las "enciclopedias" múltiples del tiempo que "todos decimos", en Ockham se convierten en un discurso monolitico que, con palabras aristotélicas, muestra el proceso de construcción del tiempo mecánico, el de los relojes. El tiempo de Ockham ya es una colección de proposiciones "sintéticas a prion" elaboradas en la subjetividad noética humana tal como se muestra en su propio discurso útil del momento histórico.

\section{Oportet prius percipere nos esse in esse transmutabili}

A partir del caso aristotélico del ciego, Ockham da en la construcción subjetiva de un movimiento - $y$ un tiempo basado en él - rapidisimo, homogéneo, infinitamente divisible... al que podemos definir en nuestra mente a partir de cualquier experiencia de sentirse ser sucesivamente o sentir algún movimiento

"Istis suppositis potest videri, quae sit intentio Commentatoris; intendit enim Commentator, quod quicumque sentit quemcumque motum, potest sentire tempus, hoc est potest apprehendere tempus esse, non tamen primo et essentialiter. Sed iste

- El Liber de Causis recoge muy bien la equivalencia mensurat-creat. 
erit processus: Aliquis [non] videns corpus coeleste moveri, apprehendit aliquem motum exteriorem vel imaginatur motum; quo facto potest imaginari se coexistere alicui uniformiter et continue moto, et per consequens ille potest apprehendere istam propositionem: ille coexistit alicui uniformiter et continue moto: et isto aprehenso apprehenditur aliquid, quod est proprium corpori coelesti moto, quia nilhil allud continue et iniformiter movetur. Et per consequens motus corporis coelestis, quamvis non sentiatur aliquo sensu tamen apprehenditur ab intellectu, non qujdem in particulari et in conceptu simplici, sed composito. Ista autem perceptione facta in anima potest fieri perceptio et sequi, qua scitur, quod aliquid uniformiter et continue, per quem motum // potest anima mensurare alios motus non continuos vel difformes: Et hoc percipere est percipere tempus.

Ex isto apparet, quod omnia dicta Commentatoris verificantur sine repugnantia. Quia in percipiendo quemcumque motum potest percipi tempus, propter hoc, quod potest anima percipere se esse in esse transmutabili, hoc est percipere se coexistere alicui uniformiter et continue moto. Bt tamen non sentitur tempus apud sentire quemlibet motum primo et asentialiter, hoc est, non immediate ex hoc, quod sentitur qucumque motus, percipitur tempus, sed oportet prius percipere nos esse in esse transmutabili modo praedicto" (De Succ. III, p. 105-106).

$\mathrm{El}$ "oportet prius percipere nos esse in esse transmutabili modo praedicto" sintetiza todo un proceso subjetivo que comienza en o al margen de los sentidos y conduce a la percepción del tiempo, una percepción que en Ockham - fiel en esto a Aristóteles - se produce en el alma (no la mente sóla, pese a todos los matices y reservas de un nominalismo que no ve facultades por parte alguna, sino totalidades nombradas) y se cataloga como un sentir.

\section{Percipimus nos coexistere alicui continue et uniformiter transmutato}

El comienzo del texto, alude a los dos párrafos anteriores, que no tienen desperdicio, pero que asegurariamos que bien poco le deben a Aristóteles. En el primero se lee

"Ex isto apparet, quod de intentione Aristotelis est, quod poterimus percipere tempus, quamvis non fuerimus moti in anima nostra, et per consequens multo fortius, quamvis non fuerimus moti in corpore nostro, et per consequens, quamvis nullo modo fuerimus moti. Et ideo quod dicit Philosophus, 'quod non percipimus tempus nisi cum percipimus nos transmutar', debet sic intelligi quod nos non percipimus tempus, nisi cum percipimus nos coexistere alicui continue et uniformiter transmutato. Bt hoc idem intelligit per omnia talia verba: 'Non percipimus tempus, nisi percipimus nos esse in esse transmutabli'" et per consimilia" (De Succ. III, p. 104 = Exp. IV, 20, 3, lins. 74-).

Es dudoso que el Filósofo, en Phys. IV, 11, 228b 20 ss., en el texto del mito de los durmientes de Cerdeña, o en contexto próximo, quiera sugerir el tema del movimiento primero. Seguramente, ni en contexto próximo ni en contexto remoto, Aristóteles sugiere lo que explica Ockham como proceso - "Sed iste erit processus:..." - dos párrafos después. Aquí Ockham se enzarza en una especie de deducción trascendental del perfecto "tiempo de relojes". 


\section{Sed tunc concipitur in conceptu particulari composito}

Y esta deducción trascendental prekantiana de la categoria de tiempo perfecto va a necesitar, efectivamente, una distinción más bien muy propia de la epistemologia del Inceptor y no poco sorprendente aplicada a este caso: la del concepto particular simple y la del concepto particular compuesto:

"Item nota, quod aliquid apprehendi potest intelligi dupliciter, vel in universali vel in particulari. Similiter potest apprehendi // vel in conceptu simplici vel in conceptu composito. Sicut in particulari apprehenditur haec albedo, quando video hanc albedinem et postea eandem intelligendo in universali apprehenditur, quando aprehenditur color in communi secundum unam opinionem, vel habetur una cognitio communis de colore secundum aliam opinionem. Sed apprehenditur aliquid in conceptu particulari simplici sicut quando ideo hanc albedinem et postea eandem intelligo. Sed tunc concipitur in conceptu particulari composito aliquid, quando habentur multi conceptus, quorum quilibet est communis illi et alteri, et tamen totum compositum ex omnibus illis est proprium illi, sicut existente hoc toto in intellectu: 'ens primum', utraque pars competit alteri a Deo, sed totum non competit nisi Deo" (Succ. III, p. 104-105 = Exp. IV, 20, 4 lins. 3-15); cfr. I Sent. d. 3, q. 2).

Es absolutamente propia de Ockham la noción de "concepto simple", signo vacio que denota un "esto" bajo un aspecto determinado de su vivencialidad por el hombre, al margen de toda similitudo, imago, vestigium, institutio tantum o mera pasividad frente al individuo singular. ${ }^{*}$ Para Ockham propiamente no puede existir un concepto simple universal: la cuantificación a través de la cual el franciscano pasa de la denotación simple del singular a la denotación del "todos los $\mathrm{X}^{\prime}$, es ciertamente una proposición, un sílogismo o un discurso más complejo, un signo complejo en definitiva." Ockham hace suya la opinión de "una cognitio communis de colore".

Pero Ockham también cree que el espiritu conoce directamente los singulares y en consecuencia puede tener un signo simple vacio y meramente denotativo, un nombre en definitiva, para un individuo. Lo que no cree es que una definición esencial del singular sea posible, si "esencial" se ha de entender en sentido tomista. Pero sí opina que se conoce esencialmente a un individuo a través de una definición esencial tal como él la concibe.

Una definición" no es un concepto, ni el "contenido" en sentido estrictisimo del concepto nominal, en estimación de Ockham. Una definición es una narración o descripción, un discurso que vincula una serie de notas o caracteristicas a un nombre. Ciertamente puede ser muy literaria, pictórica, descriptiva,... Pero, la definición esencial será exactamente aquel discurso finalistico que expresa el "¿qué es?" la cosa, cargado lógicamente con la característica de ser universal y necesario mediante las formalidades lógicas que se añaden al discurso descriptivo previo del "quid sit?" mediante dos nuevos pasos constitutivos y nada abstractivos.

1 Sent. d. 2, q. 8; OTh. II, p. 266-292.

1 Sent. Prologus, q. 2, a.2; OTh. 1, 91, 1-93, 23.

Logica Mayor, I, cap. 26; OPh. I, p. 84-89. I Sent. Prologus, q. 2, a. 2; OTh. I, 91,1-93,23. 
Desde esta perspectiva, toda definicion comienza como un discurso, un concepto compuesto particular; continua con la universalización formal, basada en el uso positivo del principio de economia; si es el caso; y acaba en discurso definitorio esencial y necesario, al presentarse bajo la forma lógica hipotética, que, exactamente, quiere decir bajo forma de bicondicional.

Una definición esencial en Ockham sigue denotanto un "esto", un singular; Ockham no acepta nada semejante a las naturae comunes de Duns Scotus, nada que pueda ser común a varios singulares $\mathrm{y}$, a la vez real. Sin ningún equivoco, para el lógico inglés no hay nada real y común que sea denotable en el conjunto de los individuos a los que se aplica la definición esencial; no existe una "escala del ser", sino que la ordenación de los conceptos se pueden hacer según su mayor o menor extensión $n^{\text {s1 }}$ y esto da solo la impresión de una "escala del ser" sin que exista un ser único de creciente o decreciente entidad.

Pero esto ocurre cuando la denotación de una definición esencial recae sobre una entidad real, un "esto" o ciertos accidentes de cualidad. En el caso de los sucesivos, estos para Ockham no existen como algo óntico, algo real: machaconamente lo repite en cada comienzo del respectivo tratadito. Sin embargo, el no tener quid rei no implica que no pueda darse una definitio essencialis del modesto quid nominis. El tiempo tiene una definitio exprimente quid nominis ¿Qué define tal definición? ¿Cual es su referente?

\section{Si una sola pars non sit in rerum natura, nec ipsum totum est}

Bs de esperar que no va a definir una nada. Serian un sueño, una flusión lo que denominaba "sucesivos" si no hubiera un algo en la realidad," que es denotado por el nombre de tiempo, movimiento y espacio, cada uno según su manera propia:

"Sic ergo patet, quod rationes, quas adducit Philosophus in principio capituli de tempore, evidenter probant, quod tempus non est aliquid extra animam distinctum secundum se totum ab omni re permanente praeterita et futura et ab omnibus rebus permanentibus, quia impossible // est, quod aliquid distinctum secundum se totum ab omnibus sit in rerum natura, nisi aliqua pars elus sit in rerum natura. Unde si una sola pars non sit in rerum natura, nec ipsum totum est. Aliter enim possem dicere, quod homo mortuus est, quia materia sua est" (Succ. III, p. 99; véase texto similar en Exp. IV, 18, 3, lins. 191-199).

"Alius sensus est iste, quod tempus significat aliquid esse praeteritum et aliquid esse futurum, et ideo in definitione exprimente quid nominis ipsius temporis debet poni tam praeteritum quam futurum, et pro tanto praeteritum et futurum dicuntur partes temporis. Nec aliud intelligunt Philosophus et Commentator, quando dicunt, quod tempus componitur ex praeterito et futuro et quod praeteritum et futurum sunt partes temporis, nisi quod praeteritum et futurum ponuntur in definitione exprimente quid nominis temporis" (Succ. III, p. 1010 Exp. IV, 18, 3, lins. 157-165).

\footnotetext{
" "Sed in hoc differunt, quod species est communis ad peuciora quam genus suum, ita quod genus est signum plurium et species pauciorum."

2 Ockham rechaza la libre institución de los signos simples mentales que propuso en su día Roscellinus de Compiege: 1 Sent. d. 2, q. 8; OTh. II, p. 266-292.
} 
Es el texto conocidisimo de las paradojas del tiempo, punto de partida del tratado sobre el tiempo en la Phys. IV,10, 217b - 218a 3) y divulgado por Agustin de Hipona. Pero lo que en Aristóteles es ínicio de la generalizada aplicación del "dividir y unificar son lo mismo sobre lo mismo", principio paradigmático de la dialéctica, no lo es en Ockham.

\section{Ita dicendum est uniformiter de omnibus succesivis. Non tamen eodem modo}

Ockham lo que percibe son 1) entidades cerradas en su substantividad incognoscible, pero permamente, mientras dura en aquello que Siger denominaba "permanencia del ser" - oponiendolo a la "plenitud de la vida" -, y 2) relaciones entre las entidades permanentes que sólo el intelecto puede captar. Estamos de nuevo, pero más a fondo, en las proposiciones contradictorias del movimiento. Más a fondo 1) porque ahora en una mayor proporción el tiempo depende del alma, y 2) porque Ockham adopta una determinada intelección del "número", acorde con ello. En efecto, èl escribe

"Verbi gratia: Hoc nomen callefactio importat, quod aliquid habet calorem et caret aliquo, quod est habituru; hoc nomen igitur calefactio importat ipsum sublectum, quod calefit, quod realiter est extra animam, et similiter importat aliquem gradum caloris, qui est in aliquo extra animam; sed praeter ista, quae sunt extra animam, importat aliquem gradum futurum caloris, qui nondum est extra animam; et ita non habet esse completum extra animam, hoc est, non quodlibed quod importatur per hoc nomen est extra animam, sed esse eius completur per actionem animae, hoc est, quidquid importatur per hoc nomen, potest cognosci ab anima.

Bt ita dicendum est uniformiter de omnibus succesivis. Non tamen eodem modo dicendum est de motu locali et de aliis, quando producuntur verae res, et hoc quia quando aliquid moveatur localiter, non oportet, quod expectetur aliqua res futura; sed sufficit, quod coexistat alicui vel coexistet in futuro, si esset aliquid ambiens, cui nondum coexistat. In aliis autem expectatur aliqua res futura, quae nondum est realiter extra animam, quamvis cognoscatur ab anima. Sic igitur patet, quomodo motus et tempus non habent esse extra animam completum, sed habent esse per animam completum, hoc est, quidquid importatur per talia potest cognoscisi ab anima.

Veruntamen sciendum, quod aliquo modo magis dependet tempus ab anima quam motus, quia sicut declarabitur, ${ }^{,}$tempus non est aliqua res distincta a motu. Immo isto modo loquendi, quo conceditur, quod motus est motus, debet concedi, quod motus est tempus, sicut postea ostenditur. Servando talem modum loquendi, ista aequivalent: (85) motus est tempus,et: motus est motus, quo anima cognoscit, quantus est alius motus. Bt ita cum illud praedicatum motus, quo aliquis cognoscit, quantus est motus alius, non possit competere aliqui sine anima, ideo impossibile est, quod motus sit tempus nisi per animam; sicut impossibile est, quod motus sit lllud, quo mensurat anima motum sine anima.

Et ita patet, quod in definitione exprimente quid nominis temporis necessario ponitur operatio animae" (Succ. III, pps. 97-98 - Exp.IV, 18, lins. 60-91; los subrayados y negritas son nuestros).

s. Exp. $I V$, cap. 20, 1-2; cap. $24,2-3$. 
El texto no tiene desperdicio. Constantemente el autor está instalado en el mundo de la predicación: ita cum illud praedicatum motus, quo aliquis cognoscit, quantus est motus alius, non possit competere aliqui sine anima es el tono de todo el fragmento.

\section{Habent esse per animam completum}

El discurso del intelecto necesita algo extra mental y, ciertamente, lo hay: por lo menos el sujeto del calentamiento, del moverse, del ser en el pasado, el presente y el porvenir, los tres tienen su puesto fuera de la mente. Pero el proceso de calentamiento, de moverse, de extensión, cambio o permanencia en el tiempo, sólo se "completa" - es abarcado o se comprende - por la acción de la mente.

Y siguen dos notas: a) se tratará de una simple relación, "non oportet, quod expectetur aliqua res futura; sed sufficit, quod coexistat alicui vel coexistet in futuro" y b) esta simple relación no es otra cosa que una predicación o conocimiento intelectual, "praedicatum motus, quo aliquis cognoscit, quantus est motus alius, non possit competere aliqui sine anima".

Con ello se produce el extraño efecto - ya existente en Aristóteles, de otra manera - de un producto meramente mental - la predicación - que resulta de alguna forma necesariamente "real", "ser de la realidad" en la auténtica dimensión verbal del "ser".

Notablemente, mientras que en Aristóteles la dimensión noética y predicamental del verbo ser acontecia en el mismisimo despliegue de la Physis, y era una acción física la misma acción predicativa, en Ockham sólo acontece en el alma humana, sólo es "mental", es decir, una de las funciones especializadas inmanentes de la entidad pensante humana. La nueva dimensión de la fisica, el "espacio" en el que se despliegan las posibilidades noéticas de la predicación arranca de un trascender y oponer la actividad mental frente a la "realidad" nouménica de la res absoluta.

Con menos claridad que en Kant, en Ockham el topos de la ciencia y su sujeto trascendental está entre el fignotum $X$ del sujeto pensante humano singular y el ignotum $X$ de la res absoluta: en un mundo de relaciones mentales que "completan" realidades ignoradas.

\section{El ser de la realidad, en la auténtica dimensión verbal del "ser"}

Naturalmente la cuestión siguiente insoslayable ha de formularse precisando el sentido del "de alguna manera necesariamente real" ¿de qué manera? Y, ¿de una manera igual en Aristóteles y en Ockham?

Se ha de reconocer que el uso del verbo predicativo "ser" en el discurso aristotélico y en el del inglés no presentan una peligrosa tendencia a la substantivación, muy patente en otros autores medievales, quizás más didácticos. Pero es muy diferente la forma en que cada autor escapa de la cosificación del verbo "ser" a partir de la feroz vivencia de la individualidad substantiva medieval, la que va acentuándose desde finales del s. XI, con el comienzo de la crisis de los universales. 
Aristóteles tiene dos líneas de fuga ante el peligro de subtantivación del verbo predicativo por antonomasia. Antes de alcanzar la unificación de la Physis en la noción del arjé-télos, le evita deslices ontologizadores su posición epistemológica fácticamente discursivo-semítica. Aquello que tantas veces se ha confundido anacrónicamente con un cierto "conceptualismo", "intelectualismo" o "geometrismo" de los Antiguos, comenzando por Sócrates y Platón, continuando en Aristóteles mismo, y aflorando en Epicuro por boca de su heredero Lucrecio, en realidad es el uso semiótico inconsciente de los signos para "construir" la realidad en una génesis more geométrico.

La segunda vía salvadora adviene al Estagirita por la impostación vital y fisiológica que el propio arjé-télos imprime a cualquiera de sus discursos. A partir de ella, toda similitud entre las expresiones y textos de los mecanicistas de la modernidad y los textos aristotélicos es un disparate anacrónico.

\section{Nondum est realiter extra animam [humanam], quamvis cognoscatur ab anima}

En Ockham, por lo contrario, no existe ni la más mínima sombra de fisiologismo cósmico. Ni tan sólo existe un tal cosmos o universo o mundo único; mucho menos existe su Psijé o su Noús-Logos. Si existe, en cambio, para Ockham, un cierto Uno, pero sólo como causa eficiente extrínseca de todas las cosas singulares; un Uno entrevisto con dudosa necesidad en una cierta reflexión a postenori del conocimiento de los singulares; un Dios Uno que nunca será visto con necesidad y claridad si el punto de partida es la proposición mental, por mucho que esté ella compuesta de elementos vivenciales acerca de la realidad.

Aristóteles con su fórmula de Vida nuclear de la Physis, Ockham con su antimetafisicismo frente al ser y las naturalezas comunes, no dirán que el "tiempo es", que los "sucesivos son". Y, sin embargo para ambos los sucesivos son reales.

Y son reales - en el sentido existencial del verbo predicativo de realidad extra-mental del siglo XX, no del suyo - no sólo de forma diferente para cada uno de los dos pensadores, sino también diferente de cómo nosotros podemos decir que son bien "reales".

Para Ockham: quando aliquid moveatur localiter, non oportet, quod expectetur aliqua res futura; sed sufficit, quod coexistat alicui vel coexistet in futuro, si esset aliquid ambiens, cui nondum coexistat. Una frase de Ockham que probablemente recoge el sentido más fuerte de la "memoria" agustiniana, resemantizándola topológicamente. Hoy, por lo contrario, los sucesivos son reales por cuanto forman parte de una descripción operativa y convencional de la "realidad", que se opone a nuestro yo noético psicológico y, a la vez, nos abarca.

Pero, son para nosotros "reales" en el grado de realidad que cada valor lingứstico otorga y requiere dentro del marco totalizador del lenguaje. Y reales como una objetivación necesaria en la globalidad de los discursos que constituyen, y por ende son siempre útiles, al yo-mundo, construido discursivamente con elementos mil veces restructurados, resemantizados, repragmatizados. 


\section{Aristóteles y la realidad de los sucesivos o continuos de la Physis}

Para Aristóteles el tiempo y los restantes sucesivos - el "continuo" sólo es un constructo propiamente inexistente, acción geométrico generativa unificadora de todo lo múltiple y sucesivo - son reales después de asentar lógica y ontológicamente la realidad del arje-telos y la Physis entre arjé $i$ telos. A final de cuentas, hablar de arjé-télos y Physis intermedia es dar la definición estructural de los tres sucesivos físicos, unificados por el dinamismo, profunda pero dialécticamente vital y motor, del noésis noéseos, zooé, muy de acuerdo en todo momento con el estructural y paradigmático "dividir y unir es lo mismo y sobre lo mismo, pese a que su ser es diferente". Movimiento, tiempo y espacio-lugar son reales simplemente porque son aspectos y modos de la única Vida; y, precisamente, son y son "pensados" en el Alma. Pero, en Aristóteles, el Alma que da realidad en el Todo a los tres sucesivos y ciertamente en modalidades muy diversas, es y sólo es el Alma que, en él, substituye al Alma de Platón.

\section{Los sucesivos físicos y el alma humana según Ockham}

Por lo contrario, el alma, la única alma que ve Ockham cuando lee al Filósofo y al Comentarista, el cordobés Averroes, es el alma humana, el espiritu subjetivo que, al vincular vivencias, se dice a si mismo quien és y donde está. Pero reservada a la Teologia la existencia y naturaleza de Dios; reservada a los tratados De Anima y a la Etica, la naturaleza y comportamiento del hombre, al tratado de la Fisica le corresponde estrictamente el "dónde está" objetivamente la pequeña alma pensante.

Y, desde la subjetividad, con semejantes acotaciones de los tratados universitarios, los sucesivos del "mundo" de Ockham serán bien reales, sin duda alguna, pero reales "mecanicisticamente" como habrán de mantenerse hasta el Kant de la Crítica de la Razón Pura. Los sucesivos son "reales" en Ockham y sus sucesores, pasando por Newton, porque y sólo porque, relacionar mentalmente unos puntos entitativos nouménicos, es eficaz para el fin que obliga a establecer las relaciones entre entidades corpóreas o a partir de las entidades.

Son reales en el mismo sentido que recogerá Leibniz tres siglos más tarde: porque son la" razón suficiente de un fenómeno" de acuerdo con el fin de la ciencia o saber que se satisface con esta razón y la declara suficiente. Por esto Ockham se manifiesta, también, satisfecho con una noción de movimiento descrita como "verificación de contradictorias sucesivas sin parada intermedia". Para nada necesita un "locus naturalis", imprescindible organicísticamente, fisiológicamente. Como le basta una temporalidad de relojero, al cual en nada le ayuda considerar una sucesión genética o histórica. Y como le satisfacerá un mero lugar por coordenadas cartesianas "equivalentes" a puntos fijos permanentes.

Bstablecer a la ciencia física entre unos entes permanentes substantivos sólo captados en la relación de fenómenos, 1) puede "salvar lo necesario" y lo que "se dice del tiempo" para una física mecánica, de cuerpos en movimiento local; y 2) es una liberación respecto al paradigma antiguo de la Physis. De hecho, suprime el lugar natural y la necesidad de un motor, y da entrada a la ley de inercia, a la distinción entre masa y peso, entre cantidad del movimiento y velocidad, etc. 
Pero 3) es también superable: no todo el mundo está de acuerdo en ver al hombre como un autómata parlante mecánico, y la superación de paradigmas mecanicistas ha creado unas nuevas fisicas - a las que aludia ya I. Düring - y unos nuevos campos para las ciencias sociales, con un sentido histórico (y, en consecuencia, semiótico) que el s. XIII perdió y hubo de reinventar Hegel en el s. $\mathrm{XIX}$, con su fenomenología de las figuras de la consciencia y su ciencia lógica.

$\mathrm{Si}$ el tiempo y el movimiento de Ockham son eminentemente y únicamente mecánicos, hoy existen muchos más juegos y funciones temporales. Surgieron precisamente de la misma brecha abierta entre la "entidad en si" y la "entidad fenoménica" ya desde las mismísimas puertas de la Modernidad y su "ciencia".

\section{El tercer sucesivo de Ockham: el lugar por equivalencia}

La reducción del movimiento y del tiempo característica del sistema de Ockham se da también en el tercer sucesivo, el lugar; un lugar que sólo aparece presupuestas unas condiciones epistemológicas de "equivalencia".

En una Physis que se despliega entre el arjé y el télos noético, el "lugar", en su último fundamento, resulta ser un "topos" perfectamente físico-noético en la corteza más exterior del Alma cósmica, como claramente establece el Liber de Causis. Propiamente, el lugar de una cosa es su definición esencial única, la que establece el Nous cósmico delimitando una determinada medida de bonitates junto a las bien acotadas medidas de bondades de los otros singulares que rodean a tal cosa singular, sin vacios intermedios que destruirian el continuo orgánico estructurado por el discurso cósmico, no realizarian aspectos determinados del Uno noético e interrumpirian su vital retomo completo sobre si. Subsumido bajo la luz del noésis noéseos, zooé, efectivamente el lugar de una cosa es el último limite del envolvente en inmediato contacto con el último límite del envuelto. Y, en el Todo noético, este lugar es fijo e inmóvil, lugar natural de cada cosa.

\section{El lugar en un cosmos de todos múltiples, autónomos e irreductibles}

Pero toda la compleja red de relaciones constitutivas de la realidad orgánica del Zoón eudaimón, quizás extrínseca a las substancias menores, pero intrínseca al Todo, se enmaraña y contradice en el momento en el que el Todo ya no explica la parte, sino que cada parte se relaciona con otra parte como si fueran una multitud de todos, autónomos e irreductibles. $\mathrm{B} l$ lugar como límite pierde completamente su significado, para quedar reducido a una contiguidad irrelevante sin el todo que aparece gracias al concepto del "continuo", en el cual todo alcanzaba un preciso significado. Ya no "localiza" nada en nada.

Ockham acusa el impacto del cambio de paradigma discursivo - del Todo a los "todos" - a partir de una de las paradojas clásicas del lugar recogidas por Aristóteles: la barca anclada en la mitad de la corriente de un rio mientras la brisa marina sopla en dirección contraria a la del agua. Pero el impacto de la paradoja en Aristóteles y en Ockham produce efectos diametralmente opuestos. 
La paradoja le sirve a Aristóteles para destacar el Todo. Ockham proclama la absoluta "formalidad" del concepto de espacio, del todo de los "todos" permanentes. Es un geometrismo sin gea que medir intrinsecamente, abstracto y absoluto, a-fisico, irreal, ya que la "formalidad" y sólo ella es la única raíz y fundamento de las totalizaciones como el "espacio" en el que localizar algo real forzosamente extrinseco. La "formalidad" lógica, para Ockham es anterior y superior al concepto de continuo, sin que alcance el nivel de la "formalidad constructivista semiótica", que para nosotros aquí y ahora es el último asequible.

\section{El lugar como "ac si" y como "inmóvil por equivalencia"}

El lugar inmóvil, efectivamente, no existe: locus non est. En efecto, no hay en el cosmos un sólo punto realmente inmóvil que permita asignar un lugar bien determinado a un cuerpo que se mueve en un momento dado o en unos momentos sucesivos. Y, sin embargo, puede imaginarse un o unos puntos "como si" fueran perfectamente inmóviles; se puede proceder a la estimación del movimiento de un móvil "ac si" realmente los puntos de referencia fueran absolutamente inmóviles. Ockham propone un "lugar formal" ante la inasibilidad e inutilidad en el s. XIV de los lugares clásicos: la contigüidad de los límites o el Alma como espacio geométrico - perfectamente uno y omnicomprensivo - concreto y real de localización.

Ockham sintetiza su sentir respecto al lugar diciendo:

"Ideo de virtute sermonis loquendo debet concedi quod locus est mobilis, quia nihil est in istis inferioribus generabilibus et corruptibilibus, quin sit mobile motu locali per se vel per accidens, quia...

Veruntamen pro intentione Philosophi est sciendum, quod Philosophus intendit dicere, quod locus est immobilis per aequivalentiam, hoc est quod tantum vales locus ad saivandum omnia, quae ponuntur de loco, ac si realiter esset immovilis, quila ita possunt in eodem loco succedere sibi diversa corpora loco non mutato, ${ }^{54}$ sicunt possunt, si locus esset simpliciter. Et ita est de omnibus aliis conditionibus propriis ipsius loci, quod ita possunt salvari sicut possent, si locus esset inmobilis simpliciter. Et nihil aliud intelligo per locum esse immobilem secundum aequivalentiam" (Succ. II, p. 8687; vide también Succ. II, p. 73-74).

La frase clave es "ita possunt in eodem loco succedere sibi diversa corpora loco non mutato". El fragmento recoge el primero de los argumentos de Aristóteles en Phys. IV, 1; 208b 1-5, a través de los cuales el filósofo griego muestra a) que "el lugar es algo que presenta muchas dificultades, porque si se lo considera según todas sus propiedades no parece ser lo mismo".

* Ctr. Bxp. IV, 1 (3), OPh. V, p. 5: "Prima ratio est ista: illud in quo aliqua corpota sibi mutuo succedunt est aliquid distinctum ab eis. Sed in loco corpora sibl sscocedunt mutuo, quia in eodern loco in quo nunc est aqua postea est aer. Ergo locus est aliquid distinctum ab eis, et per consequens locus est." Fragmento que recoge el primero de los argumentos de Aristóteles en Phys. IV, 1; 208b 1-5. 


\section{Pro intentione Philosophi est sciendum, quod...}

En esta introducción de Phys. IV, 1 a la problemática, Aristóteles, además, b) ya plantea la dificultad en la forma ternaria general de "lo uno y lo otro son lo mismo y en relación a lo mismo, pese que en su ser son diferentes". De esta manera, aquí y en este primer argumento, se juega con "lugar-aire", "lugar-agua", "lugar", pese a que "aire" y "agua" son "diferentes". Al Filósofo, c) este paradigma dialéctico le lleva a un constructo conceptual (singladura semiótica: continuo) y de aquí a una realidad inversora y realizadora de todo lo pensado (arjé-télos noético) en un discurso que goza del consenso de todos, y en tanta realidad cuanta exija tal discurso.

Como de costumbre, Ockham apeará el arjé-telos a "subjetividad noética humana" y el "consenso de todos" quedará en consenso de especialistas. El filósofo natural inglés ignorará la terna dialéctica en favor de una definición plana (sujeto = def. descriptiva) del quid nominis de una variable, que resultará apta para ser incluida en un algoritmo de la ciencia en cuestión, siempre un conocimiento parcial y bien determinado fácticamente.

Pero, en el caso del lugar, Ockham tropieza con la "variable" más absolutamente objetivada de las tres que intervienen en la fisica de los cuerpos móviles, la que menos dominable parece con argucias de la razón: el cuerpo es espaciallocalizado por si mismo pero en este aspecto no es móvil, si bien puede ser mutable; los cuerpos se mueven por un espacio real, o no se podrán mover, no ya faltos del empuje de un motor, sino también pese a un motor. En efecto, algo debe permanecer fijo o no hay forma de constatar el movimiento si absolutamente todo se mueve ordenadamente, etc., en la rica secuencia de paradojas que Ockham lee en Aristóteles.

Ockham geometriza como el Filósofo, pero la geometria del franciscano es puramente mental y no generativa: son las coordenadas a priori y permanentes (en sí, pero sólo aplicadas mientras es necesario aplicarlas), lógicas y matemáticas, gracias a las cuales se localiza un cuerpo ac si ellas fueran realmente inmóviles, en un tercer cielo o mundo popperiano de coordenadas cartesianas.

A nuestra vez y en el siglo veinte, nosotros también tenemos una geometría mental: pero es una geometria variable porque define semióticamente el proceso del vivir cotidiano en toda su riqueza: es aquella red de preguntas de hoy con signos heredados del pasado como acervo cultural, que pesca los peces de la "realidad" global en la pequeña pecera que está a nuestro alcance humano. La red de Wittgenstein también es una geometria, pero no a priori, sino de facto y convencional, e histórica en cualquier caso. 